Aus der Klinik für Pädiatrie mit Schwerpunkt Onkologie und Hämatologie der Medizinischen Fakultät Charité - Universitätsmedizin Berlin

\author{
DISSERTATION
}

\title{
Fenretinide sensitizes multidrug-resistant human neuroblastoma cells to antibody-independent and ch14.18-mediated NK cell cytotoxicity
}

\author{
zur Erlangung des akademischen Grades \\ Doctor medicinae (Dr. med.)
}

vorgelegt der Medizinischen Fakultät

Charité - Universitätsmedizin Berlin

von

\author{
Anastasia Shibina \\ aus Grjasi, Russland
}


Gutachter/in: 1. Prof. Dr. med. H. Lode

2. Prof. Dr. P. Lang

3. Prof. Dr. med. A. Eggert

Datum der Promotion: 30.11.2012 


\section{Abbreviations}

4-HPR fenretinide or $\mathrm{N}$-(4-hydroxyphenyl) retinamide

13-CRA 13-cis-retinoic acid

A ampere

ADCC antibody-dependent cell-mediated cytotoxicity

$\mathrm{ACT}$ adoptive cell transfer

APS antigen presenting cell

$\mathrm{CD}$ cluster of differentiation

CDC complement-dependent cytotoxicity

CDR complementarity determining region

Cyt C cytochrome C

DC dendritic cell

DED death effector domain

DISC death-inducing signaling complex

DNA deoxyribonucleic acid

DR death receptor

EFS event-free survival

ELISA enzyme linked immunosorbent assay

FACS fluorescence activated cell sorting

Fab-fragment fragment with the antigen binding sites

FADD Fas-associated death domain Fc-fragment fragment crystallizable

FasL Fas ligand

Fig. figure

GCS glucosylceramide synthase

GrB granzyme B

GM-CSF granulocyte-macrophage colony-stimulating factor

GvHD graft versus host disease

GvT graft versus tumor

h hours

HACA human anti-chimeric antibody

HAMA human anti-mouse antibody

HLA human leukocyte antigen

HSCT hematopoietic stem cell transplantation

HSC hematopoietic stem cell

Ig immunoglobulin 
IC immunocytokines

IFN interferon

IL interleukin

KIR killer cell Ig-like receptor

LGL large granular lymphocytes

$\mathrm{mAb} \quad$ monoclonal antibodies

MAC membrane attack complex

MHC major histocompatibility complex

M molar

NB neuroblastoma

NCR natural cytotoxicity receptor

NK cells natural killer cells

OS overall survival

PBMCs peripheral blood mononuclear cells

PPPP d,1-threo-1-phenyl-2-hexadecanoylamino-3-pyrrolidino-1-propanol

RNA ribonucleic acid

ROS reactive oxygen species

S1P sphingosine-1-phosphate

SPT serine palmitoyl transferase

TNF tumor necrosis factor

TRAIL TNF related apoptosis inducing ligand

V volt

ULBP UL16-binding protein 


\section{Abbreviation}

1. Introduction $\quad 2$

1.1. Neuroblastoma 2

1.2. Immunotherapy 3

1.2.1. Antibodies and their functions 3

1.2.1.1. ADCC (antibody-dependent cell-mediated cytotoxicity) 6

1.2.1.2. CDC (complement-dependent cytotoxicity) 7

1.3. NK cells 8

1.3.1. AICC or DR pathway 9

1.4. Immunotherapies for neuroblastoma 11

1.4.1. Vaccines 11

1.4.2. Cytokine therapy for neuroblastoma 11

1.4.3. GD2 and anti-GD2 antibody immunotherapy 12

1.4.4. Immunocytokines 13

1.4.5. Cellular therapies for neuroblastoma 13

1.5. Fenretinide and ceramide metabolism 14

1.6. Hypothesis 16

2. Material and methods 17

$\begin{array}{ll}\text { 2.1. Material } & 17\end{array}$

2.1.1. Chemicals 17

2.1.2. Cell lines 18

2.1.3. Cell culture media and supplements 18

$\begin{array}{ll}\text { 2.1.4. Antibodies } & 18\end{array}$

2.1.5. Kits 19

2.1.6. Special laboratory reagents and buffers 19

2.1.7. Special laboratory tools 19

2.1.8. Special laboratory equipment 20

2.1.9. Softwares 20

2.2. Methods 20

2.2.1 Cell culture 20

2.2.2. Ficoll-Paque preparation of human blood mononuclear cells 21

2.2.3. Preparation and culture of expanded NK cells 21

2.2.4. Drug treatment 21

2.2.5. Flow cytometric analysis 22

$\begin{array}{ll}\text { 2.2.6. Cytotoxicity assays } & 22\end{array}$ 
2.2.6.1. CDC 23

2.2.6.2. ADCC 23

2.2.6.3. AICC 23

2.2.7. Granzyme B (GrB) and perforin ELISA 24

2.2.8. Western Blot analysis 25

2.2.9. Mouse xenograft experiments 25

2.2.9.1. Tumor induction and treatment procedure 26

2.2.9.2.Ex vivo ADCC assay $\quad 26$

2.2.9.3. Analysis of tumor-infiltrating NK cells 26

$\begin{array}{ll}\text { 2.2.10. Statistical analysis } & 27\end{array}$

3. Results 28

3.1. GD2 expression of 4-HPR-resistant human NB cells increases upon $\begin{array}{ll}\text { treatment with 4-HPR } & 28\end{array}$

3.2. Fenretinide increases ch14.18-mediated effector mechanisms 29

3.2.1. 4-HPR enhances ch14.18/CHO-mediated CDC of 4-HPR-resistant human NB cells $\quad 29$

3.2.2 4-HPR enhances ch14.18/CHO-mediated ADCC of 4-HPR-resistant human NB cells by peripheral blood mononuclear cells 30

3.3. Fenretinide treatment enhances AICC and ch14.18/CHO-mediated ADCC by purified NK cells towards 4-HPR-resistant human NB cell lines

3.4. Effect of 4-HPR treatment on Fas and TRAIL-R2 expression on neuroblastoma cells $\quad 32$

3.5. Inhibition of AICC after DR-blocking 32

3.6. Granzyme B and perforin production by PBMCs in response to activation with fenretinide-treated NB cells

3.7. Disruption of ganglioside synthesis leads to an abrogation of 4-HPR-mediated increase in ch14.18-dependent ADCC and CDC 34

3.7.1. Effect of 4-HPR and PPPP on GCS expression 34

3.7.2. Effect of the inhibition of GCS with PPPP on GD2 expression 34

3.7.3. Effect of the inhibition of GCS with PPPP on 4-HPR-mediated increase in ch14.18/CHO-dependent ADCC and CDC

3.8. Effect of 4-HPR treatment on NK cell mediated killing in neuroblastoma Xenografts

3.8.1. Effect of 4-HPR treatment on GD2, Fas and TRAIL-R2 expression on neuroblastoma cells in vivo 
3.8.2. Fenretinide treatment enhances AICC and ch14.18/CHO-mediated

ADCC by purified NK cells towards 4-HPR-resistant human NB CHLA-136 cell line ex vivo

3.8.3. Treatment with 4-HPR mediates increased tumor infiltration by NK cells in vivo

4. Discussion

5. Summary

6. Literature

7. Appendix

Curriculum Vitae

Publications

Acknowledgment 


\section{Introduction.}

\subsection{Neuroblastoma.}

Neuroblastoma is a tumor that originates from the sympathetic nervous system. It is the most common extracranial tumor in childhood and about $90 \%$ of children diagnosed with neuroblastoma are less than 5 years old [1]. Most tumors develop within the adrenal glands; others arise in the mediastinum, cervical region or pelvis. The location of tumors, along with the absence or presence of dissemination, leads to a wide spectrum of symptoms and signs. The most common symptoms are pain, fever, and weight loss.

The molecular biology of neuroblastoma is diverse and characterized by overexpression of oncogenes, gene inactivation (tumor suppressor genes), or alterations in gene expression. Amplification of the MYCN proto-oncogene occurs in $20 \%$ to $25 \%$ of neuroblastomas and is a reliable marker of aggressive clinical behavior, reduced progression-free survival and poor outcome [2]. Interestingly, $>10 \%$ of tumors undergo complete spontaneous regression in the absence of or with minimum treatment [3]. This situation is generally associated with stage $4 \mathrm{~S}$ disease (S for "special"), defined as a localized primary tumor with dissemination limited to skin, liver and/or bone marrow in infants less than 1 year old.

Unfortunately, nearly $50 \%$ of the patients show a high-risk phenotype at diagnosis, characterized by widespread metastases and poor long-term survival despite intensive multimodal therapy. Standard treatment includes multi-agent, high dose chemotherapy, surgical removal of the primary tumor, radiotherapy and autologous or allogeneic bone marrow transplantation followed by treatment of minimal residual disease with 13-cis-retinoic acid (isotretinoin). The five-year eventfree survival (EFS) in high-risk neuroblastoma patients, who received standard therapy, has increased in the past decade to $40 \%$ (Fig. 1.1)[4].

Fig. 1.1: Kaplan-Meier curves for event-free survival and overall survival in high-risk neuroblastoma.

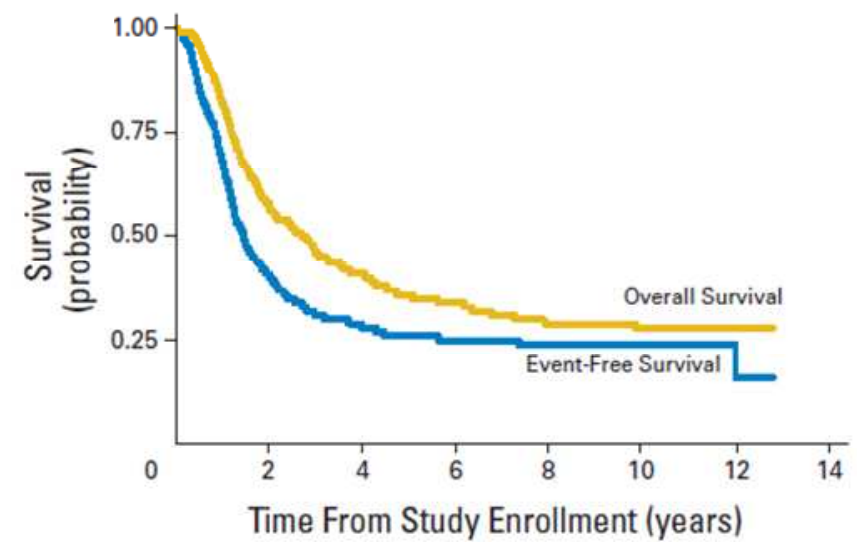

The overall 5-year event-free survival (EFS) and overall survival (OS) for all patients $(n=539)$. The overall EFS and OS were $26 \% \pm 2 \%$ and $36 \% \pm 2 \%$ respectively [4]. 
This means that more than half of the patients with high-risk neuroblastoma will have disease recurrence and not survive the disease, emphasizing the need for development of new and powerful alternative approaches to treat this disease. One such alternative therapy that holds promise is immunotherapy.

\subsection{Immunotherapy.}

Immunotherapeutic approaches are used in order to induce, enhance, or suppress an immune response, depending on the disease. Cancer immunotherapy attempts to stimulate the immune system and to enable it to specifically recognize and destroy tumors. Immunotherapeutic strategies can be divided into active or passive approaches. Active immunotherapy, including cancer vaccines, is designed to stimulate the host immune system to develop a targeted immune response. There are several vaccination approaches under current laboratory and clinical investigation such as protein/peptide vaccines, DNA vaccines, antigen presenting cell (APC)-based vaccines and recombinant viral/bacterial vectors expressing particular tumor antigen vaccines. Active immunotherapy is used in order to generate a long-lasting immune response against tumor antigens, which may provide future immune surveillance resulting in delayed tumor recurrence and prolonged survival.

On the other hand, passive immunotherapy provides more transient effects and involves the repeated administration of "ready to use" cytokines, antibodies, or the adoptive transfer of immune effector cells.

\subsubsection{Antibodies and their functions.}

The concept that antibodies can be used for the treatment of malignant diseases originated more than a century ago [6], but antibody-based immunotherapy first became practical reality with the development of the hybridoma technology. Hybridoma technology made it possible to produce a large number of anticancer monoclonal antibodies (mAbs), specifically targeting antigens that are expressed on the surface of tumor cells. Anticancer mAbs have been utilized for the immunotherapy of a variety of malignancies, such as breast, colon, and hematological cancers and their application demonstrated the improvements in time to disease progression and overall survival $[6,7,8,9]$.

An antibody or immunoglobulin (Ig) is a "Y"-shaped molecule that consists of four polypeptide chains: two identical light chains (L chain) and two identical heavy chains (H chain). Each chain is composed of structural domains called immunoglobulin domains. These domains contain about 70-110 amino acids. The light chain has two immunoglobulin domains, whereas the heavy chain of the antibody contains four. The first domain at the amino terminus of both the heavy $\mathrm{H}$ and light $\mathrm{L}$ chains varies greatly between different antibodies and is called variable or $\mathrm{V}$ domain (VH and VL) (Fig. 1.2.1) [6]. 
Fig. 1.2.1: Schematic structure of an antibody and antibody fragments after cleavage with papain.

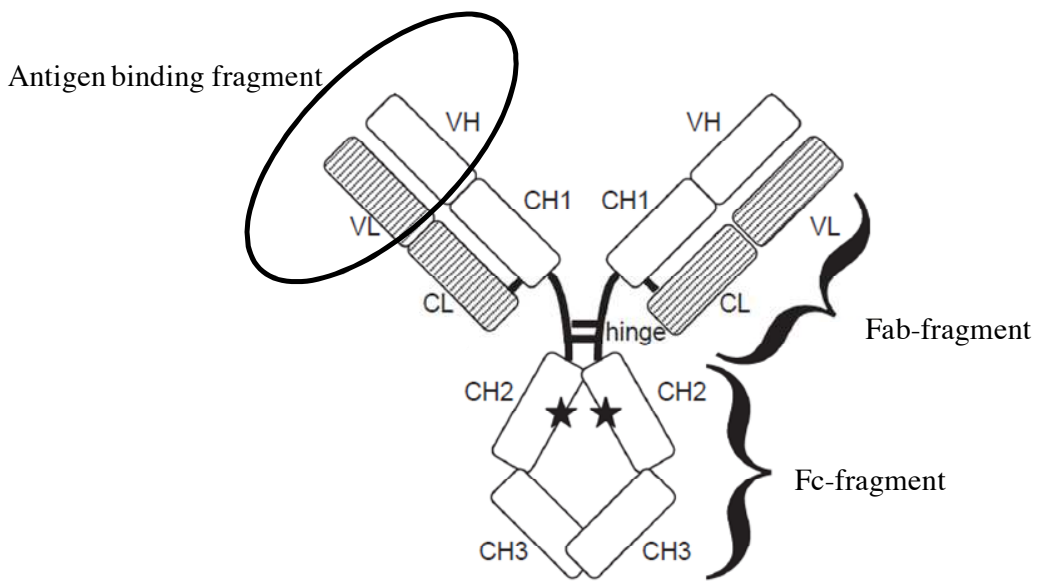

Each antibody molecule consists of two identical light chains (L chain) (grey shaded) and two identical heavy chains (H chain) (white chains). Each chain has variable (V) and constant (C) regions. Heavy chains are covalently paired by disulfide bonds in hinge regions, and each heavy chain is connected to a light chain by a disulfide bond between $\mathrm{CH} 1$ and CL. The Fab-fragment contains the complete light chains paired with the $\mathrm{VH}$ and $\mathrm{CH} 1$ domains of the heavy chains and provides for the antigen binding site. The Fc-fragment consists of paired $\mathrm{CH} 2$ and $\mathrm{CH} 3$ domains. In the $\mathrm{CH} 2$ domains of the Fc regions, an oligosaccharide is covalently attached to the both domains (black star) [6].

Comparisons of the amino acid sequences of the variable regions of Igs revealed that most of the variability resides in three regions called the hypervariable regions or the complementarity determining regions (CDRs). The regions between the CDRs in the variable region are called the framework regions. The $\mathrm{V}$ domain of the heavy and light chain pairs in each arm of the $\mathrm{Y}$ generate two identical antigen-binding sites. The remaining regions of the heavy and light chains are called constant regions ( $\mathrm{CH}$ and $\mathrm{CL}$, respectively), since there is only little variation in the amino acid sequence of this region among antibodies belonging to the same class. The multiple heavy-chain $\mathrm{C}$ domains are numbered starting from the amino-terminal end to the carboxy-terminus $(\mathrm{CH} 1, \mathrm{CH} 2$, CH3). The heavy and light chains are held together by disulfide bonds and by non-covalent interactions. The region at which the arms of the antibody molecule form a $\mathrm{Y}$ is called hinge region. This region can be cleaved by the proteolytic enzyme papain resulting in the formation of three fragments: two identical Fab-fragments (Fab-fragment with the antigen binding sites), and one fragment crystallizable (Fc-fragment).

The Fab-fragment, which exhibits antigen-binding activity, contains the complete light chains paired with the $\mathrm{VH}$ and $\mathrm{CH} 1$ domains of the heavy chains. In contrast, the Fc-fragment, containing the remainder of the two heavy chains $(\mathrm{CH} 2$ and $\mathrm{CH} 3)$, provides effector function by interacting with immune effector cell receptors $(\mathrm{Fc} \gamma \mathrm{R})$, and the $\mathrm{C} 1$ component of the complement system. The major interaction sites of the Fc-fragment are located within the hinge region and $\mathrm{CH} 2$ domain, and binding is dependent on the glycoform of the oligosaccharides attached to the $\mathrm{CH} 2$ domains [6]. The effector mechanisms mediated via the Fc-fragment can be severely abrogated in aglycosylated or deglycosylated forms of IgG molecule [10]. 
Based on differences in the amino acid sequences in the constant region of the heavy chains, the immunoglobulins can be divided into classes and subclasses, exhibiting different properties. Five classes of immunoglobulins (IgG, $\operatorname{IgA}$, $\operatorname{IgM}$, IgE, and $\operatorname{IgD}$ ), as well as two $\operatorname{IgA}$ subclasses (IgA1, IgA2) and four IgG subclasses (IgG1, IgG2, IgG3, and IgG4) are present in humans. IgG can be bound by molecules of the complement system, resulting in complement activation, and natural killer cells, macrophages, and monocytes. In contrast, $\operatorname{IgA}, \operatorname{IgE}$ and $\operatorname{IgD}$ cannot bind to molecules of the complement system but are able to activate effector cells. IgA can bind to macrophages, monocytes and $\operatorname{IgE}$ to basophils and mast cells. $\operatorname{IgM}$ is the first antibody to appear in response to initial exposure to an antigen and it normally exists as a pentamer. Due to its polymeric nature, IgM can provide high avidity toward complement and strong complement activation. However, this class of Ig only binds to some effector cells. Most therapeutic antibodies belong to the IgG class due to the it ability to induce strong complement and effector cell activation in contrast to the other Ig classes and subclasses [11,12].

Depending on the origin, mAbs can be divided into murine, chimeric, and humanized antibodies. Murine mAbs are produced utilizing hybridoma technology following immunization of mice. Because all components are derived from the mouse, murine antibodies induce a so-called human anti-mouse antibody (HAMA) immune response, when applied in a human setting, and the Fc-fragment of this antibody may not elicit effector function as effectively as the Fc-fragment of a human antibody. A chimeric antibody, which combines the murine antigen-binding variable region and the human constant regions, provides effector function comparable to a human antibody, but it still can induce production of the antibodies: human "anti-chimeric" antibody (HACA). In contrast to that, a humanized antibody is created in order to reduce the immunogenicity of a murine antibody, by grafting the CDRs of the murine antigen-binding variable regions into a human $\operatorname{IgG}$ molecule (Fig. 1.2.2) [13,14].

Antibodies, as a part of the humoral immune system, contribute to immunity in three different ways: i) they can neutralize pathogens and toxins by binding them; ii) they stimulate removal of opsonized pathogens by effector cells; iii) they trigger the destruction of pathogens through an activation of the complement system. In tumor immunology, antibodies play a significant role because of their ability to mediate destruction of tumor cells through two different mechanisms: antibody-dependent cell-mediated cytotoxicity (ADCC) and complement-dependent cytotoxicity (CDC). 
Fig. 1.2.2: Schematic structure of different types of genetically engineered antibodies.

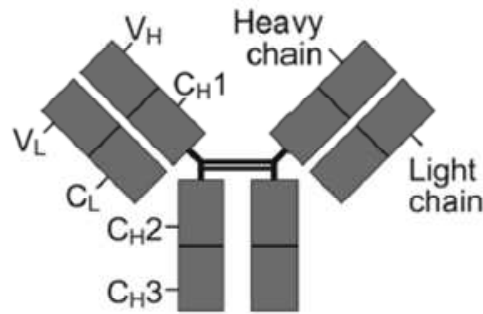

A. Mouse



B. Chimeric

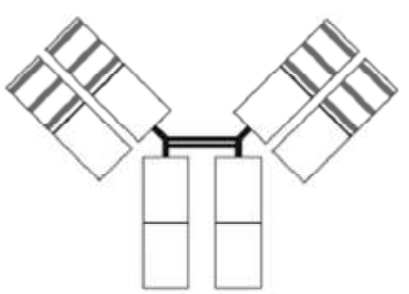

C. Humanized

A. A murine antibody is produced utilizing hybridoma technology following immunization of mice. All components are mouse-derived. B. A chimeric antibody combines the murine antigen-binding variable region and the human constant regions. C. A humanized antibody is created by grafting the complementarity determining-regions of the murine antigen-binding variable regions into the human IgG molecule [14].

\subsubsection{ADCC (antibody-dependent cell-mediated cytotoxicity).}

Classical ADCC is mediated by natural killer (NK) cells, neutrophils or eosinophils. ADCC involves the binding of antibodies to the target cell via its antigen binding region (Fab-fragment). This process is called opsonization. Once the antibodies are bound to the target cells, the Fcfragment of the antibody can be recognized and bound by Fc-receptors on effector cells (Fc $\gamma$ RIII, CD16), resulting in the secretion of cytokines such as IFN- $\gamma$ as well as the release of cytolytic effector molecules, i.e. perforin and granzymes, from cytolytic granules into the immunological synapse between effector and target cell. Polymerization of perforin molecules within the target cell membrane results in pore-formation, thereby facilitating the entry of granzymes into the target cell [11].

Fig. 1.2.1.1: ADCC.
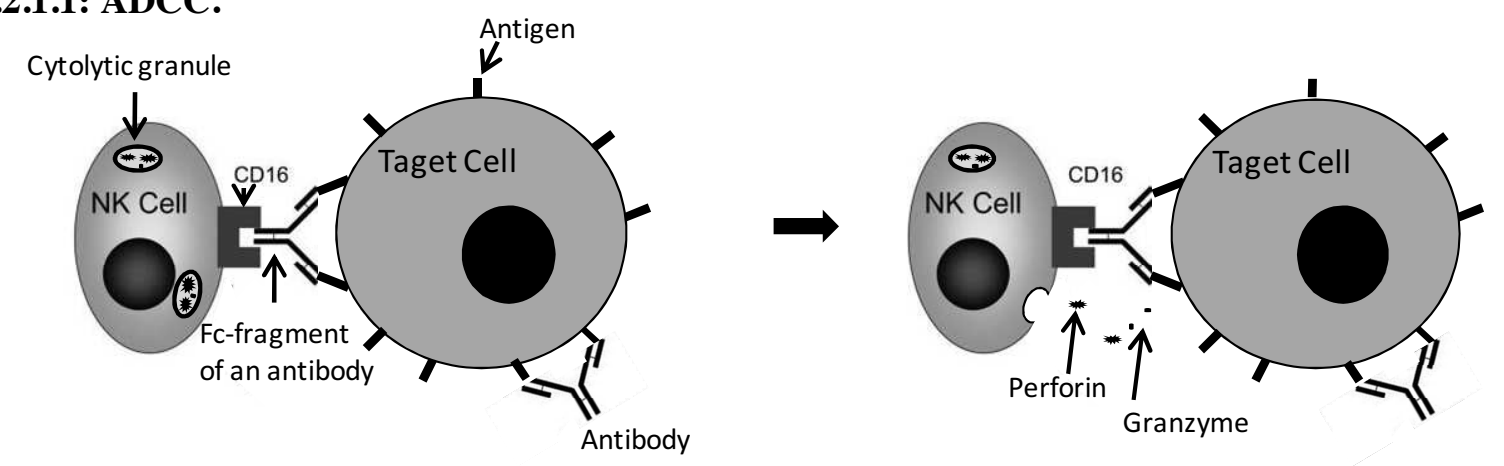

A typical ADCC involves activation of NK cells by antibodies. The NK cell CD16 or Fc-receptor recognizes the Fc-fragment of an antibody, which has bound to surface antigens on a target cell. Once the Fc-receptor binds to the Fc-fragment of the antibody, the NK cell releases cytokines, and cytotoxic granules containing perforin and granzymes (Modified from [18]).

Granzymes are a distinct family of serine proteases. The expression of granzymes is restricted to $\mathrm{T}$ cells and natural killer cells [15]. To date, five different granzymes have been described in humans: granzymes A, B, H, K and M [16]. The most powerful pro-apoptotic member 
of the granzyme family is granzyme $\mathrm{B}(\mathrm{GrB})$. $\mathrm{GrB}$ can promote apoptosis either by direct activation of the caspase-cascade or by induction of the intrinsic apoptosis pathway. GrB is able to direct proteolytic activation of the executor caspases-3 and caspase-7, which leads to caspase-mediated degradation of hundreds of cellular protein substrates and subsequently to apoptosis. The induction of the intrinsic apoptosis pathway is mediated by GrB-promoted Bid-dependent mitochondrial permeabilization, followed by release of Cytochrome $\mathrm{C}$ into the cytosol, assembly of the apoptosome, with subsequent caspase-9 activation and the ensuing caspase cascade resulting in the efficient killing of the target cell [17].

\subsubsection{CDC (complement-dependent cytotoxicity).}

The second effector mechanism that is involved in Ab-mediated destruction of infected or malignant cells is the activation of the complement system. It is triggered by activation of the C1complex, which occurs when $\mathrm{Clq}$ binds to $\mathrm{IgM}$ or $\mathrm{IgG}$ complexed with antigens. Such binding causes conformational changes in the $\mathrm{C} 1 \mathrm{q}$ molecule, leading to the activation of two $\mathrm{C} 1 \mathrm{r}$ (a serine protease) molecules, which results in the cleavage of $\mathrm{C} 1 \mathrm{~s}$ (another serine protease). The $\mathrm{C} 1 \mathrm{r} 2 \mathrm{~s} 2$ component now splits $\mathrm{C} 4$ and then $\mathrm{C} 2$, producing $\mathrm{C} 4 \mathrm{a}, \mathrm{C} 4 \mathrm{~b}, \mathrm{C} 2 \mathrm{a}$, and $\mathrm{C} 2 \mathrm{~b} . \mathrm{C} 4 \mathrm{~b}$ and $\mathrm{C} 2 \mathrm{a}$ bind to form the classical pathway $\mathrm{C} 3$-convertase ( $\mathrm{C} 4 \mathrm{~b} 2 \mathrm{a}$ complex), which promotes cleavage of $\mathrm{C} 3$ into $\mathrm{C} 3 \mathrm{a}$ and $\mathrm{C} 3 \mathrm{~b}$; $\mathrm{C} 3 \mathrm{~b}$ later joins with $\mathrm{C} 4 \mathrm{~b} 2 \mathrm{a}$ (the $\mathrm{C} 3$ convertase) to produce $\mathrm{C} 5$ convertase (C4b2a3b complex), which cleaves C5 into C5a and C5b. C5b rapidly associates with C6 and C7 and inserts into the membrane. Subsequently C8 binds, followed by several molecules of C9. The C9 molecules form a pore in the membrane, through which the cellular contents leak out and lysis occurs. The complex consisting of $\mathrm{C} 5 \mathrm{bC} 6 \mathrm{C} 7 \mathrm{C} 8 \mathrm{C} 9$ is referred to as the membrane attack complex (MAC) (Fig. 1.2.1.2) [11]. 
Fig. 1.2.1.2: CDC.



$\mathrm{CDC}$ is initiated by the binding of $\mathrm{C} 1$ complex of complement system to the Fcfragment of $\operatorname{IgG}$ and $\operatorname{IgM}$ antibody molecules that have interacted with antigen. This binding results in activation of the $\mathrm{C} 1$ complex, which cleaves $\mathrm{C} 2$ into $\mathrm{C} 2 \mathrm{a}$ and $\mathrm{C} 2 \mathrm{~b}$, and $\mathrm{C} 4$ into $\mathrm{C} 4 \mathrm{a}$ and $\mathrm{C} 4 \mathrm{~b}$. The resulting $\mathrm{C} 4 \mathrm{bC} 2 \mathrm{a}$ complex is a $\mathrm{C} 3$ convertase, which cleaves $\mathrm{C} 3$ into $\mathrm{C} 3 \mathrm{a}$ and $\mathrm{C} 3 \mathrm{~b} . \mathrm{C} 3 \mathrm{~b}$ is joining the $\mathrm{C} 4 \mathrm{bC} 2 \mathrm{a}$ complex to make a $\mathrm{C} 5$ convertase, which splits C5 into C5a and C5b. C5b with C6, C7, C8, and C9 (C5b6789) form the membrane attack complex (MAC), which is inserted into the cell membrane, forms a pore and initiates cells lysis (Modified from [19]).

\subsection{NK cells.}

Natural killer (NK) cells are a component of the innate immune system and account for about $10-15 \%$ of the peripheral blood lymphocytes in humans. They are primarily involved in immunosurveillance to eliminate transformed and virally-infected cells. Although originally named for their capacity to elicit cytotoxicity, NK cells are also a potent source of cytokines and chemokines, especially interferon (IFN)- $\gamma$, tumor necrosis factor (TNF)- $\alpha$, and granulocytemacrophage colony-stimulating factor (GM-CSF). In addition to direct effects on the tumor and virally-infected cells, these cytokines can promote the differentiation, activation and/or recruitment of other immune cells $[20,21]$.

Due to the presence of dense intracellular cytolytic granules, containing the effector molecules perforin and granzyme B, they are defined as large granular lymphocytes (LGL). Phenotypically, NK cells are characterized by their expression of CD56 and lack of expression of CD3. Human NK cells can be divided into two subsets based on their cell surface density of CD56. The majority (90\%) of human NK cell has low-density expression of CD56 (CD56 ${ }^{\mathrm{dim}}$ ) and express high levels of Fc receptor (CD16+), whereas $10 \%$ of NK cells shows high-density expression of CD56 (CD56 ${ }^{\text {bright }}$ ) and low or no expression level of Fc-receptor. Based on their phenotypic 
Introduction

properties, CD $56^{\mathrm{dim}} \mathrm{NK}$ cells exhibit a major natural cytotoxicity. In contrast, CD56 ${ }^{\text {bright }} \mathrm{NK}$ cells have capacity to produce large amount of cytokines, but have low natural cytotoxicity [22].

The activation of NK cells is tightly regulated by the interaction of activating and inhibitory receptors expressed on NK cells with their respective ligands on the surface of target cells. Two main types of NK cell inhibitory receptors have been described: inhibitory killer cell Ig-like receptors (KIR) and the heterodimeric NKG2A/CD94 receptor. Inhibitory KIR recognize subsets of the classical MHC-I molecules (human leukocyte antigens (HLA) -A, -B, and -C), while NKG2A/CD94 detects the non-classical MHC-I molecule, HLA-E. Engagement of inhibitory KIR and CD94/NKG2A with the ubiquitous MHC-I molecules on the surface of most cells leads to NK cell tolerance towards normal cells $[23,24]$.

Receptors contributing to the activation of NK cells are NKG2D, the activating KIR, and the natural cytotoxicity receptors (NCR) NKp30, NKp44, and NKp46. NKG2D recognizes nonclassical MHC-I molecules, such as MICA/MICB and UL16-binding proteins (ULBPs). The activating KIR recognizes classical MHC-I molecules, whereas the identification of the ligands for NCR has only recently begun $[23,25]$.

Tumor cell recognition by NK cells is based on recognition of activating ligands expressed on the surface of tumor cells as well as low or absent expression of the inhibiting class I major histocompatibility complex (MHC-I) molecules. MHC-class I molecules are normally expressed on every cell of the body but it has been shown that malignant transformation of cells or viral infection can result in down regulation of MHC-I. Thus, MHC class I expression is down-regulated in many neuroblastomas [26]. Down-regulated MHC-I expression allows them to escape detection by cytolytic T cells but simultaneously makes abnormal cells sensitive to recognition by NK cells.

NK cells mediate their cytotoxicity by two major mechanisms that require direct contact between NK cells and target cells: ADCC and antibody-independent cellular cytotoxicity (AICC), including the death receptor (DR) pathway.

\subsubsection{AICC or DR pathway.}

This pathway is triggered by binding of the Fas ligand (FasL) or TRAIL (TNF related apoptosis inducing ligand) on NK cells to death receptors (DRs) that are expressed on target cells. DRs belong to the tumor necrosis factor (TNF) receptor superfamily, which is characterized by a conserved intracytoplasmic "death domain" (DD). Several family members have been identified in mammalian cells: Fas (or CD95/Apo1), TRAIL receptor 1 (TRAIL-R1, DR4) and TRAIL receptor 2 (TRAIL-R2, DR5, KILLER), DR3, DR6 and the TNF-receptor [27]. The best-characterized death receptor pathways are the Fas and TRAIL-R1/R2 pathways (Fig. 1.3.1). 
Fig. 1.3.1: Schematic overview of DR-induced apoptosis.



Binding of TRAIL to TRAIL-R1 or TRAIL-R2 leads to receptor trimerisation and formation of the deathinducing signalling complex (DISC). The adaptor protein FADD (Fas-associated death domain) is recruited to the DISC where the death domains (DD) of both proteins interact. Subsequently, pro-caspases 8 and 10 are recruited to the DISC where they interact with FADD via their death effector domains (DEDs). DISCactivated caspases 8 and 10 then trigger a caspase cascade by cleavage of caspase-3. In addition, Bid is cleaved into tBid, which initiates the mitochondrial apoptosis pathway leading to release of Cytochrome $\mathrm{c}$ $(\mathrm{CytC})$. CytC, together with apoptotic protease activating factor 1 (Apaf-1) forms the apoptosome, an activation platform for caspase-9, thereby allowing for full activation of caspases 3 and 9, ultimately leading to cell death. The intrinsic, Bcl-2-controlled, pathway is also triggered after extensive DNA damage. BH3only proteins PUMA and Noxa are up-regulated, thereby altering the ratio of pro-apoptotic and antiapoptotic Bcl-2-family members, allowing for mitochondrial depolarization and cell death (Modified from [28]).

The interaction between receptor and ligand results in receptor trimerisation and recruitment of the specific adapter molecule FADD (Fas-associated death domain). The binding of FADD to the receptor complex via their DDs then promotes the recruitment of procaspases 8 and 10. This complex of FADD, procaspase 8 and procaspase 10 is called the death-inducing signaling complex (DISC). FADD and procaspases 8 and 10 contain death effector domains (DEDs) and it is likely that homotypic interaction between their DEDs leads to the activation of caspases 8 and 10. In some types of cells (type I), processed caspase-8 directly activates effector caspases and triggers the execution of apoptosis of the cell. In other types of cells (type II), the Fas-DISC starts a feedback loop that results in increasing release of Cytochrome $\mathrm{C}$ from mitochondria, forming the 
apoptosome, an activation platform for caspase- 9 , followed by full activation of caspases-3 and 9 and cell death $[28,29,30]$.

\subsection{Immunotherapies for neuroblastoma.}

Immunotherapy of malignant diseases has gained more and more attention over the past decade. Common immunotherapeutic strategies for treatment of neuroblastoma consist of vaccines, cytokines, anticancer antibodies, immunocytokines and cellular therapies.

\subsubsection{Vaccines.}

Active immunotherapy with cancer vaccines holds a potential for establishing long-lasting and specific antitumor immunity. Different vaccination types have been developed and evaluated in preclinical studies and/or in early phase clinical trials. In neuroblastoma, DNA-vaccines targeting tyrosine hydroxylase [31], GD2 [32] and survivin [33] showed anti-tumor activity in murine neuroblastoma models. However, the next step from bench to bedside still needs to be taken, which is currently hampered by the high costs of GMP-DNA production for human use.

On the other hand, dendritic cell (DC)-based vaccines have already been tested in Phase I clinical trials for neuroblastoma patients. In order to assemble DC vaccines, DCs were harvested from patients by leukapheresis and exposed to autologous tumor lysates [34] or to autologous tumor RNA [35]. Vaccinations were well tolerated by patients, the major side effect being local allergic reactions. Unfortunately, the anti-tumor responses in the DC vaccine trials were not significant. However, both studies demonstrated that administration of these vaccines is safe and feasible in pediatrics patients.

\subsubsection{Cytokine therapy for neuroblastoma.}

Cytokines are small protein molecules that are secreted mostly by cells of the immune system and belong to a category of signaling molecules used as mediators and regulators of immune processes. Based on the functions and the source of cytokines, they can be divided into monokines (cytokines produced by mononuclear phagocytic cells), lymphokines (cytokines produced by activated lymphocytes), interleukins (cytokines that act as mediators between leukocytes), and chemokines (small cytokines primarily responsible for leukocyte migration). Cytokines act as a network and play a critical role in regulating the immune system. Some cytokines can also stimulate the differentiation of hematopoietic cells, e.g. GM-CSF [11].

Due to reduced immunocompetence of neuroblastoma patients after receiving standard multi-agent treatment, neuroblastoma can be a potential target for cytokine therapy. Therefore, exogenous cytokines may be used to stimulate the patients' immune response against residual 
neuroblastoma. Cytokines such as interleukin-2 (IL-2), IL-12 [36], and IL-27 [37] either as a single agent or in combination have demonstrated antitumor efficacy in preclinical neuroblastoma models. Furthermore, IL-2 and GM-CSF have been shown to increase the therapeutic efficacy of mAbs in clinical trials $[38,39]$. Thus, application of IL-2 and GM-CSF demonstrated enhanced NK cell cytotoxicity as well as ADCC of macrophages and granulocytes, resulting in improved overall efficacy of the antibody therapy for neuroblastoma $[39,40,41]$.

\subsubsection{GD2 and anti-GD2 antibody immunotherapy.}

The most advanced immunotherapy for neuroblastoma patients is antibody therapy directed against disialoganglioside GD2, which is highly expressed on tumors of neuroectodermal origin including neuroblastoma and melanoma [42]. Its function is not completely understood, but it is thought to play an important role in the attachment of tumor cells to extracellular matrix proteins [43]. GD2 expression in normal fetal and adult tissues is primarily restricted to the neurons, skin melanocytes and peripheral nerve fibers [44]. Due to its high and relatively tumor-specific expression, GD2 is an attractive target for tumor-specific antibody therapy.

Several anti-GD2 antibodies such as 3F8 (murine antibody), 14G2a (murine antibody), ch14.18 (human-mouse chimeric antibody) and hu14.18 (humanized antibody) have been developed and tested in preclinical and clinical studies over the past decades.

Both murine antibodies 3F8 and 14G2a have demonstrated only minimal antitumor activity and high immunogenicity resulting in the generation of a human anti-mouse antibody-HAMA, which limited the anti-neuroblastoma effect of antibody therapy. Side effects of antibody treatment most commonly included pain, hypertension, hypotension, fever, vomiting, diarrhea, and urticaria. Pain can be dose-limiting and has been attributed to antibody recognition of peripheral nerve fibers expressing GD2. In addition, the Fc-fragment of the murine antibody may not elicit ADCC or CDC as effectively as the Fc portion of a human antibody, as described above $[45,46,47,48,49]$.

To overcome these problems, Gillies et al developed the human-mouse chimeric monoclonal antibody ch14.18, combining genes for murine 14G2a variable regions and human constant region genes for IgG1 heavy and light chains [50]. The antigen binding properties of ch14.18 are identical to the ones of the equivalent mouse antibody but the chimeric antibody ch14.18 is more efficacious in mediating ADCC of NB cells than murine 14G2a [51].

The GD2-specific chimeric antibody ch14.18 generated in SP2/0 hybridoma cells (ch14.18/SP2/0) has undergone several preclinical and clinical trials as a single-agent therapy as well as in combination with GM-CSF or recombinant (r) IL-2. Recently, a phase III study performed by the Children's Oncology Group (COG) in the US evaluated whether a combination of immunotherapy including ch14.18/SP2/0, GM-CSF and rIL-2 and standard maintenance therapy 
with 13-cis-retinoic acid (13-CRA) may improve outcome for patients with high-risk neuroblastoma who responded to induction therapy and stem cell transplant. The results from this trial revealed an increased two-year event-free survival of $66 \%$ in the immunotherapy group (ch14.18/SP2/0 + GM$\mathrm{CSF}+\mathrm{rIL}-2+13-\mathrm{CRA})$ versus $46 \%$ in the standard treatment group (13-CRA alone) $(\mathrm{p}=0.0115)$. Overall survival at two years was $86 \%$ for the immunotherapy group versus $75 \%$ for the standard treatment group $(p=0.016)$ [52]. It has been shown for the first time that the inclusion of immunotherapy in standard therapy provides a clinical benefit with improved event-free and overall survival for children with high-risk neuroblastoma, highlighting the role of immunotherapy in treatment of this challenging disease.

\subsubsection{Immunocytokines.}

Immunocytokines (ICs) are tumor reactive mAb genetically linked to cytokines, such as IL2, via their Fc-fragment. Due to the recognition of a tumor-associated antigen by the mAb component, the IC molecule can bind to the tumor and deliver high concentrations of the cytokine directly to the tumor microenvironment, which attracts immune effector cells. Several ICs based on chimeric and humanized anti-GD2 antibodies have been developed and tested preclinically and in initial clinical trials. Importantly, the IC ch14.18-IL2 demonstrated a higher antitumor activity in mouse models in contrast to comparable amounts of mAb and IL-2 given as separate molecules [53]. Furthermore, it has been reported, that the IC induced activation of natural killer cells through Fc and IL-2 receptors [54] as well as activation of T cells through IL-2 receptors [55]. These data suggest that ICs could function as both a T-cell inducing vaccine as well as an activator of ADCC, providing a new strategy to elicit an effective cellular immune response mediated by NK and T cells against neuroblastoma.

\subsubsection{Cellular therapies for neuroblastoma.}

Cellular therapies for neuroblastoma include hematopoietic stem cell transplantation (HSCT) and adoptive cell transfer. Based on the origin of the transplant, HSCT can be classified into two fundamentally different types: autologous and allogeneic transplantation. Autologous HSCT requires the harvest and storage of a patient's own hematopoietic stem cells (HSC). The introduction of HSCT made possible the administration of the high-dose chemotherapy with a regimen beyond the tolerance of the bone morrow (myeloablative regimen). Infusion of stored stem cells into the patient replaces destroyed tissue and induces hematopoietic recovery. A recent clinical study showed that treatment with high-dose chemotherapy followed by autologous HCST improved event-free survival among children with high-risk neuroblastoma [56]. 
In contrast, during allogeneic HSCT patients receive blood-forming stem cells from HLAmatched donors. Unfortunately, alloreactive T-cells of the donor can recognize the recipient cells as "foreign" and attack them, resulting in the development of "graft versus host disease" (GvHD) and transplantation related mortality. Interestingly, GvHD is often associated with a graft versus tumor (GvT) effect, in which alloreactive T-cells induce destruction of the tumor cell [57].

Several adoptive cell transfer (ACT) strategies including infusion of ex-vivo expanded and/or genetically modified T cells [58,59], NK cells [60] or LAK cell transfer [61] have been tested in preclinical and in small clinical studies. Although only a few patients demonstrated response to these therapies, these studies revealed that using immunotherapeutic approaches, particularly adoptive cell transfer, is safe and feasible.

In summary, immunotherapy has emerged as a promising optimization of neuroblastoma treatment. Preclinical and clinical studies have identified multiple mechanisms contributing to successful immunotherapies. These findings provide the baseline for the design of new clinical protocols combining different immunotherapeutic approaches and applying it for the treatment of minimal residual disease.

\subsection{Fenretinide and ceramide metabolism.}

Fenretinide or $\mathrm{N}$-(4-hydroxyphenyl) retinamide (4-HPR) is a synthetic derivative of vitamin A that mediates anti-tumor activity in preclinical and clinical studies [62]. 4-HPR showed only minimal toxicity in humans [63] and induces cytotoxicity in cancer cells via generation of reactive oxygen species (ROS) [64,65] and primarily intracellular accumulation of ceramides, causing both apoptosis and necrosis [66].

Ceramides are sphingolipids involved in mediating important cellular activities such as induction of growth arrest, cell differentiation, senescence and apoptosis in some human cancer cells [67]. They can be generated in cells by two main pathways. First, they can be produced via de novo synthesis from serine and palmitoyl-CoA through the action of serine palmitoyl transferase (SPT). Alternatively, ceramide can be generated by agonist-induced activation of sphingomyelinase, which catalyzed hydrolysis of membrane-derived sphingomyelin to ceramide and phosphocholine [68]. On the other hand, there are several mechanisms of ceramide degradation or clearance, such as metabolization by ceramidases to sphingosine, which can be phosphorylated by sphingosine kinases to generate sphingosine-1-phosphate (S1P). Further, glucosylceramide synthase (GCS) converts ceramides into glucosylceramides, which leads to the formation of lactosylceramides and subsequently gangliosides, including the disialogangliosides GD3 and GD2 (Fig 1.5) [69]. 
Fig 1.5: Pathways of ceramide generation and metabolism.

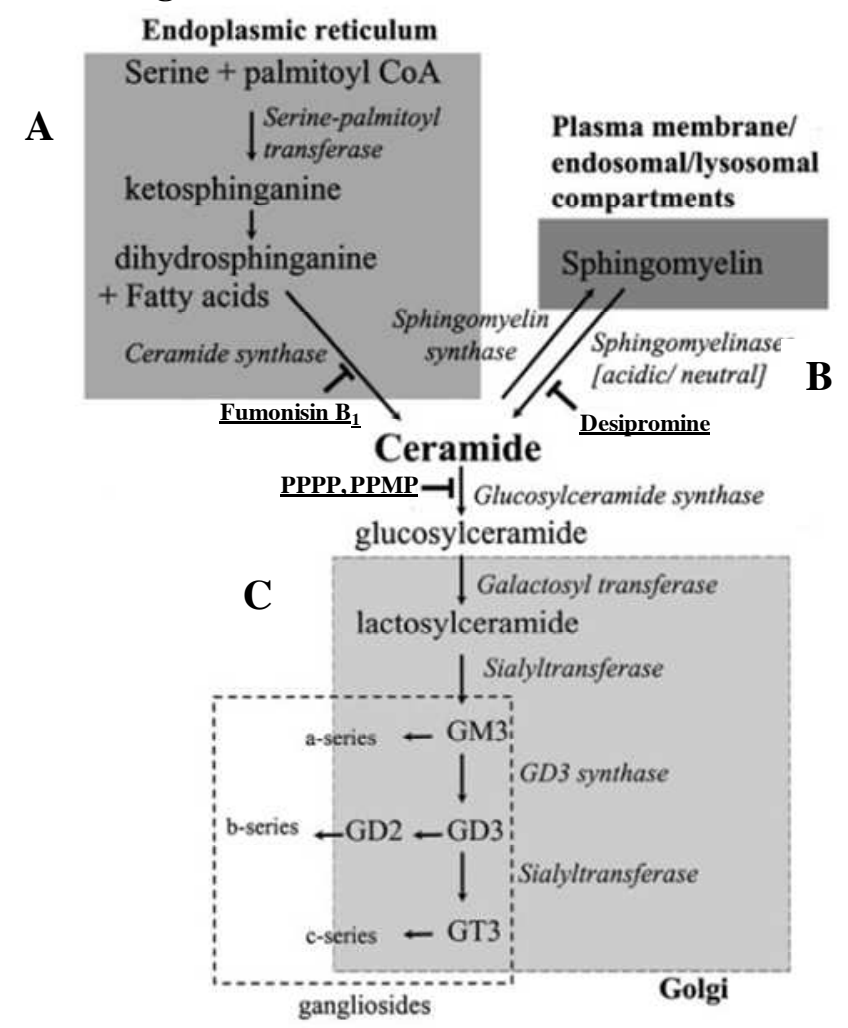

Ceramides can be metabolized by multiple pathways in a cell. They can be generated via de novo synthesis from serine and palmitoyl CoA (A) through the action of serine palmitoyl transferase (SPT) or via hydrolysis of membrane-derived sphingomyelin by sphingomyelinases (B). Ceramides subsequently are metabolized to glucosylceramides, lactosylceramides, and gangliosides of the a-, b-, and c-series (C). Enzymes involved in the metabolism of ceramides are shown in italics. Inhibitors of these enzymes are commercially available (underlined) [69].

Interestingly, multi-drug resistant tumor cells often exhibit an increased activity and/or expression of enzymes involved in ceramide clearance to prevent ceramide accumulation and ceramide induced apoptosis [70,71,72]. In 4-HPR-resistant ovarian carcinoma cells, increased ganglioside levels were demonstrated after treatment with 4-HPR compared to 4-HPR sensitive cells [73]. These data suggest that 4-HPR might be able to enhance GD2-directed immunotherapy via an increased GD2 expression on 4-HPR-resistant NB cells mediated by an evasion mechanism from toxic ceramide accumulation.

Another interesting immunomodulatory function of 4-HPR could recently be shown in Ewing sarcoma cells: Here, treatment resulted in an up-regulation of death receptors, which was correlated with an enhanced apoptosis induced by exogenously applied DR ligands [74]. Since NK cells mediate both ADCC and antibody-independent cytotoxicity via DRs, an up-regulation of death receptors by human NB cells could enhance their susceptibility to NK cells lysis. 
Introduction

\subsection{Hypothesis}

Accordingly, the hypothesis of this work was: Pre-treatment with 4-HPR will sensitize multidrug-resistant human neuroblastoma cells to antibody-independent and ch14.18-mediated NK cell cytotoxicity. 


\section{Material and methods.}

\subsection{Material.}

\subsubsection{Chemicals.}

- $\quad N$-(4-hydroxyphenyl)retinamide (4-HPR), MW=391.258/mol (kindly provided by Barry J. Maurer, TTUHSC)

- d,1-threo-1-phenyl-2-hexadecanoylamino-3-pyrrolidino-1-propanol (PPPP), MW=495.2/mol (kindly provided by Barry J. Maurer, TTUHSC)

- Sodium chloride $(\mathrm{NaCl})$ (Sigma-Aldrich)

- Potassium chloride (KCl) (Sigma-Aldrich)

- Glucose (Sigma-Aldrich)

- $\quad$ Sodium hydrogen carbonate (NaHCO3) (Sigma-Aldrich)

- Phenol Red (Sigma-Aldrich)

- HEPES buffer (Sigma-Aldrich)

- $100 \%$ ethanol (Sigma-Aldrich)

- Phosphate-buffered saline (PBS) (MP Biomedical, Solon, OH)

- Bovine serum albumin (BSA) (Hyclone, Logan, UT)

- Ethylenediaminetetraacetic acid (EDTA) (Sigma-Aldrich)

- Sodium azide $\left(\mathrm{NaN}_{3}\right)$ (Mallinckrodt chemicals, Phillipsburg, $\mathrm{NJ}$ )

- Ficoll-Paque ${ }^{\mathrm{TM}}$ PLUS (GE Healthcare, Pittsburgh, PA)

- Diamidino-phenylindole (DAPI) (Sigma-Aldrich)

- Sodium ortho-vanadate (Sigma-Aldrich)

- Sodium fluoride (Sigma-Aldrich)

- $100 \%$ methanol (Sigma-Aldrich)

- Nonfat dry milk (Bio-Rad Laboratories)

- Tween 20

- 4-HPR/LYM-X-SORB oral powder (kindly provided by Barry J. Maurer, TTUHSC)

- Ammonium chloride $\left(\mathrm{NH}_{4} \mathrm{Cl}\right)($ Sigma-Aldrich)

- Potassium hydrogen carbonate $\left(\mathrm{KHCO}_{3}\right)$ (Sigma-Aldrich)

- Triton X-100 (Sigma-Aldrich)

- Acetic acid (Sigma-Aldrich)

- Sulfuric acid $\left(\mathrm{H}_{2} \mathrm{SO}_{4}\right)$ (Sigma-Aldrich) 


\subsubsection{Cell lines.}

All cell lines were kindly provided by C. Patrick Reynolds, TTUHSC.

- CHLA-15 (human neuroblastoma cell line established at diagnosis before therapy)

- CHLA-20 and SK-N-BE(2) (human neuroblastoma cell lines established at time of progressive disease during or after nonmyeloablative therapy)

- CHLA-79, CHLA-136, and CHLA-172 (human neuroblastoma cell line established at time of progressive disease after myeloablative therapy)

\subsubsection{Cell culture media and supplements.}

- RPMI 1640 and IMDM media (Hyclone Laboratories, Logan, UT)

- L-Glutamine (CellGro, Mediatech Inc. Manassas, VA)

- heat-inactivated FBS (GIBCO, Invitrogen, Carlsbad, CA)

- ITS Culture Supplement (insulin and transferrin $5 \mathrm{mg} / \mathrm{ml}$ each, and $5 \mathrm{ng} / \mathrm{ml}$ of selenious acid) (BD Biosciences, San Jose, CA)

- $\quad$ interleukin 2 (IL-2) (Aldesleukin, Novartis, Emeryville, CA)

- Cryoprotective Freezing Medium (Lonza)

- Matrigel $^{\mathrm{TM}}$ Basement Membrane Matrix (BD Biosciences, Lot number 354234, Bedford, MA)

\subsubsection{Antibodies.}

- ch14.18/CHO (kindly provided by SIOPEN-group)

- PE-labeled anti-human IgG antibody (cat. no. 555787, BD Biosciences, San Jose, CA)

- anti-CD20 antibody (Rituximab, MabThera, Roche, Germany)

- anti-CD3 antibody (cat. no. 560176, BD Biosciences)

- anti-CD16 antibody (cat. no. 561313, BD Biosciences)

- $\quad$ anti-CD56 antibody (cat. no. 559043, BD Biosciences)

- $\quad$ anti-CD95 (Fas) antibody (cat.no. MC-063, Kamiya Biomedical, Seattle, WA)

- $\quad$ anti-TRAIL-R1 antibody (cat.no. ALX-804-297, Enzo Life Sciences, Plymouth Meeting, PA)

- anti-TRAIL-R2 antibody (cat.no.ALX-804-298, Enzo Life Sciences, Plymouth Meeting, PA)

- PE-labeled rat anti-mouse IgG1 antibody (cat.no. 550083, BD Biosciences)

- mouse anti-human GCS antibody (Abnova, Taipei City, Taiwan)

- peroxidase-conjugated goat anti-mouse IgG1 antibody (GE Healthcare, Amersham, Buckinghamshire, UK) 
- mouse anti- $\beta$-actine antibody (Santa Cruz Biotechnology, Santa Cruz, CA)

- peroxidase-conjugated goat anti-mouse IgG1 (Amersham, Buckinghamshire, UK).

- anti-mouse NK1.1 FITC-conjugated antibody (cat. no. 553164, BD Biosciences)

- FITC-labeled mouse IgG2A, K isotype antibody (cat.no. 553456, BD Biosciences)

\subsubsection{Kits.}

- CytoTox 96 non-radioactive cytotoxicity assay (Promega, Madison, WI)

- Human Granzyme B ELISA Kit (MabTech, Mariemont, $\mathrm{OH}$ )

- Human Perforin ELISA Kit (MabTech, Mariemont, OH)

- enhanced chemiluminescence (ECL) detection system (Amersham, Buckinghamshire, UK)

\subsubsection{Special laboratory reagents and buffers.}

- RosetteSep Human NK Cell Enrichment Cocktail (Stemcell Technologies)

- trypan blue $0.4 \%$ solution (Sigma-Aldrich)

- FcR Blocking reagent (Miltenyi)

- TMB substrate reagent (Substrate Reagent Pack, R\&D Systems)

- RIPA buffer (Sigma-Aldrich)

- Bio-Rad Protein Assay (Bio-Rad Laboratories, Hercules, CA)

- 4X SDS Sample Buffer (Novagen, San Diego, CA)

- SDS running buffer (cat. no. FB60500, C.B.S. Scientific, Del Mar, CA)

- transfer buffer (SSC Buffer 20x) (cat. no. 161-0774, Bio-Rad)

\subsubsection{Special laboratory tools.}

- EDTA coated blood collection tube (cat. no. 366643, BD Biosciences, San Jose, CA)

- serum tube containing clot activator and gel for serum separation (cat. no. 367988, BD Biosciences, San Jose, CA)

- $10-20 \%$ triethanolamine sodium dodecyl sulfate precast gel (C.B.S Scientific, Del Mar, CA)

- Polyvinylidene difluoride (PVDF) membrane (Protran, Keene, NH)

- $70 \mu \mathrm{m}$ cell strainer (cat. no. 352350, BD Bioscience)

\subsubsection{Special laboratory equipment.}

- LSRII flow cytometer (BD Biosciences) 
- microplate reader (Bio-Rad Benchmark Microplate Reader)

- Dual Vertical Mini-gel system (cat. no. MGV-402, C.B.S. Scientific, Del Mar, CA)

- Owl HEP-3 Semi Dry Electroblotting System (Thermo Scientific)

\subsubsection{Softwares.}

- FACSDiva software (BD Biosciences)

- FlowJo software (TreeStar, Ashland, OR)

- GraphPad Prism software (GraphPad Software, San Diego, CA)

\subsection{Methods.}

\subsubsection{Cell culture.}

The following GD2 ${ }^{+}$neuroblastoma cell lines were used in our experiments: CHLA-20, CHLA79, CHLA-136, CHLA-172, and SK-N-BE(2). All these cell lines are considered highly 4-HPRresistant with an IC90 $>10 \mu \mathrm{M}$ as described previously [87] or as determined within our group (unpublished data). Cell line CHLA-15 is moderately 4-HPR-resistant with an IC90 of $6.2 \mu \mathrm{M}$. All cell lines except SK-N-BE(2) were cultured in IMDM medium supplemented with heat-inactivated $20 \%$ FBS, $4 \mathrm{mM} \mathrm{L-Glutamine,} \mathrm{insulin} \mathrm{and} \mathrm{transferrin} 5 \mathrm{mg} / \mathrm{ml}$ each, and $5 \mathrm{ng} / \mathrm{ml}$ of selenious acid (ITS Culture Supplement). SK-N-BE(2) was cultured in RPMI 1640 supplemented with 10\% heatinactivated FBS. All cell lines were cultured at $37^{\circ} \mathrm{C}$ in a humidified incubator containing $5 \% \mathrm{O}_{2}$ and $5 \% \mathrm{CO}_{2}$ and were subjected routinely to Mycoplasma testing at the Cell Culture Core of the Cancer Center at Texas Tech University Health Sciences Center (Lubbock, TX). Cell line identities were confirmed by short tandem repeat profiling as previously described [88]; short tandem repeats were unique for all cell lines.

NB cells were subcultured at 80-90\% confluency by using a modified Puck's Solution A plus EDTA (Puck's EDTA) for splitting, which contains $140 \mathrm{mM} \mathrm{NaCl}, 5 \mathrm{mM} \mathrm{KCl}, 5.5 \mathrm{mM}$ glucose, $4 \mathrm{mM}$ NaHCO3, 0.8 mM EDTA, 13 mM Phenol Red, and 9 mM HEPES buffer (pH 7.3) [89].

Cells were frozen in cryoprotective medium diluted 1:1 with heat-inactivated FBS at concentration $5-10 \times 10^{6} / \mathrm{vial}$. In order to provide optimal cooling rate of $-1^{\circ} \mathrm{C}$ to $-3^{\circ} \mathrm{C}$ per minute, cell containing vials were placed in an isopropanol chamber and stored at $-80^{\circ} \mathrm{C}$ for $72 \mathrm{~h}$. After freezing for $72 \mathrm{~h}$, vials were removed from the isopropanol chamber and transferred to their final storage locations in liquid nitrogen. 


\subsubsection{Ficoll-Paque preparation of human blood mononuclear cells.}

Peripheral blood mononuclear cells (PBMCs) were isolated from blood from healthy volunteers using $10 \mathrm{ml}$ EDTA coated blood collection tubes. Blood was transferred into new $50 \mathrm{ml}$ tube and diluted 1:1 with ice-cold phosphate-buffered saline (PBS). $12.5 \mathrm{ml}$ of Ficoll-Paque ${ }^{\mathrm{TM}}$ PLUS was placed into a new 50ml tube followed by carefully overlaying with $20 \mathrm{ml}$ PBS-diluted blood. Density gradient centrifugation was performed at $375 \mathrm{~g}$ without brakes for $30 \mathrm{~min}$ at $4^{\circ} \mathrm{C}$. The layer including PBMCs was carefully removed with a sterile Pasteur pipette and cells were washed 3 times with complete RPMI 1640 medium. PBMCs were plated out into cell culture flasks and cultured for 3 days in complete RPMI 1640 medium supplemented with $100 \mathrm{IU} / \mathrm{ml}$ interleukin 2 (IL-2) at $37^{\circ} \mathrm{C}$ in a humidified incubator containing $5 \% \mathrm{O}_{2}$ and $5 \% \mathrm{CO}_{2}$ before being subjected to cytotoxicity assays.

\subsubsection{Preparation and culture of expanded NK cells.}

NK cells were expanded from PBMCs isolated from a healthy donor as previously described [90]. Briefly, PBMCs were stimulated weekly with irradiated (100Gy) K562 $\mathrm{Cl} 9^{\mathrm{mIL} 21}$ at an effector-to-target (E:T) ratio of 1:2 in NK cell expansion media (comprised of RPMI, 10\% FBS, $100 \mathrm{IU} / \mathrm{ml}$ penicillin, $100 \mu \mathrm{g} / \mathrm{ml}$ streptomycin, $2 \mathrm{mM} \mathrm{L-Glutamine}$ and $50 \mathrm{IU} / \mathrm{ml}$ of $\mathrm{IL}-2$ ) at $37^{\circ} \mathrm{C}$ in $5 \% \mathrm{CO}_{2}$, to selectively expand NK cells. At the end of two stimulations NK cells were isolated using RosetteSep Human NK Cell Enrichment Cocktail and expanded further for one week following third stimulation with irradiated $\mathrm{K} 562 \mathrm{Cl} 9^{\mathrm{mIL} 21}$. The NK cells were phenotyped to assess purity by flow cytometry using antiCD3, anti-CD16 and anti-CD56 antibodies and then cryopreserved. RosetteSep purification depletes CD3 cells and expanded NK cells were less than 1\% CD3 positive. Expanded frozen NK cells were cultured in RPMI1640 including 10\% FBS, $100 \mathrm{IU} / \mathrm{ml}$ IL-2 for 4-5 days prior to a cytotoxicity assay. NK cell expansion was performed in the laboratory of Dean A. Lee, MD, PhD, at the MD Anderson Cancer Center, Huston, Texas. All experiments involving human specimens were approved by the Institutional Review Board (IRB) of the Texas Tech University Health Sciences Center.

\subsubsection{Drug treatment.}

4-HPR ( $N$-(4-hydroxyphenyl)retinamide, MW=391.258/mol) and glucosylceramide synthase (GCS) inhibitor PPPP (d,1-threo-1-phenyl-2-hexadecanoylamino-3-pyrrolidino-1-propanol, MW=495.2/mol) were diluted in $100 \%$ ethanol. All neuroblastoma cells were plated out at a concentration of 5 to $10 \times 10^{5} / 3 \mathrm{ml}$ into the wells of a 6 well plate and allowed to attach over night. 4HPR was added the next day in a final concentration of 5 or 10 (or $2.5 \mu \mathrm{M}$ for CHLA-15) $\mu \mathrm{M}$ and cells 
were incubated at $37^{\circ} \mathrm{C}$ in a humidified incubator containing $5 \% \mathrm{O}_{2}$ and $5 \% \mathrm{CO}_{2}$ for 48 hours. In order to block GCS function, cells were treated with $1 \mu \mathrm{M}$ PPPP for 4 to 5 days as previously described [86]. Control cells were treated with the same volume of $100 \%$ ethanol (vehicle control). Prior to following assays, dead cells in the supernatant were removed by pipetting and gentle washing with medium. Adherent cells were counted and only cell populations with at least $95 \%$ viable cells, as determined by trypan blue staining, were used for further analysis.

\subsubsection{Flow cytometric analysis.}

For FACS analysis, $1 \times 10^{6}$ cells were washed once in $500 \mu$ FACS buffer (PBS containing $1 \%$ BSA, $0.1 \%$ EDTA and $0.1 \% \mathrm{NaN}_{3}$ ). For analysis of GD2 expression, cells were stained with $1 \mu \mathrm{g}$ ch14.18/CHO in $100 \mu \mathrm{l}$ FACS buffer for 10-15 minutes. After washing twice with FACS buffer, cells were stained for 10-15 min with PE-labeled anti-human IgG secondary antibody at a dilution of 1:5. Cells were again washed twice and pellets were resolved in $300 \mu \mathrm{FACS}$ buffer and subjected to FACS analysis. As an isotype control we used chimeric anti-CD20 antibody. Death receptors were stained with the following antibodies for $45 \mathrm{~min}$ : $0.5 \mu \mathrm{g}$ anti-CD95 (Fas), $0.5 \mu \mathrm{g}$ anti-TRAIL-R1 and $1 \mu \mathrm{g}$ anti-TRAIL-R2. All antibodies are murine IgG1. As a secondary antibody we used a PE-labeled rat anti-mouse IgG1 antibody in a dilution of 1:200 for $20 \mathrm{~min}$.

To exclude dead cells from analysis, cells were stained with DAPI (final concentration 0.1 $\mu \mathrm{g} / \mathrm{ml}$ ), which was added shortly before analysis. For each cell sample 20,000 live cells were analyzed by the LSRII flow cytometer using FACSDiva software. Final data analysis was done with FlowJo software. From live and PE-labeled cells (=GD2 positive or death receptor positive) we calculated the binding indices: mean fluorescence $\mathrm{x} n \%$ positive cells/100 [87].

\subsubsection{Cytotoxicity assays.}

All assays were performed using the CytoTox 96 non-radioactive cytotoxicity assay, according to the manufacturer's protocol. Each experiment included spontaneous and maximum release determination and controls and was performed in 8 replicates in a U-bottom microtiter plate. Maximum release was induced by adding $15 \mu \mathrm{l}$ of lysis solution (Triton X-100) to the respective wells (final concentration of Triton X-100 is $0.8 \%$ ) 45 min before the end of indicated time points ( $6 \mathrm{~h}$ for CDC, 4 $\mathrm{h}$ for ADCC and AICC). After 45 min incubation with lysis solution, $50 \mu \mathrm{l}$ of supernatant was transferred from each well into a new 96 flat-bottom enzymatic assay plate. $50 \mu$ of substrate mix was added to each well followed by incubation in the dark for $30 \mathrm{~min}$ at room temperature (RT). Reaction 
was stopped using stop solution (acetic acid). Absorbance was measured at $490 \mathrm{~nm}$ using a standard microplate reader.

\subsubsection{CDC.}

For CDC assays, human serum of one donor with identified low spontaneous lytic activity against neuroblastoma was used as a source of complement. Serum was prepared by collecting the whole blood into serum tube containing clot activator and gel for serum separation. The whole blood was incubated for $10 \mathrm{~min}$ at RT followed by centrifugation at $1000 \mathrm{~g}$ for $10 \mathrm{~min}$. Serum was removed from the clot by gently pipetting into a clean tube.

CDC assays were carried out by seeding of $1 \times 10^{4}$ target cells per well in $100 \mu$ of PRMI 1640 . Serum was diluted in RPMI 1640 medium and added to the wells in $75 \mu 1$ (final concentration of serum in a well was 10\%). Antibodies ch14.18/CHO and anti-CD20 (control) were added in $25 \mu 1$ into the respective wells in a final concentration of $10 \mu \mathrm{g} / \mathrm{ml}$. Plates were incubated at $37^{\circ} \mathrm{C}\left(5 \% \mathrm{O}_{2}\right.$ and $5 \%$ $\mathrm{CO}_{2}$ ) for $6 \mathrm{~h}$. Lysis solution was added after $5 \mathrm{~h}$ and $15 \mathrm{~min}$

\subsubsection{ADCC.}

Effector cells (PBMCs or expanded NK cells) were harvested and plated at an E:T ratio of 25:1 (for PBMCs) and 5:1 or 2.5:1 (for NK cells), respectively, in 75 $\mu 1$ RPMI supplemented with 5\% heatinactivated FBS. Target cells were added at a concentration of $1 \times 10^{4}$ cells in $100 \mu$ RPMI 1640 (10\% FBS). Antibody ch14.18/CHO and anti-CD20 control were added in a final concentration of $1 \mu \mathrm{g} / \mathrm{ml}$ and plates were incubated at $37^{\circ} \mathrm{C}\left(5 \% \mathrm{O}_{2}\right.$ and $\left.5 \% \mathrm{CO}_{2}\right)$ for $4 \mathrm{~h}$. Lysis solution was added after $3 \mathrm{~h}$ and $15 \mathrm{~min}$.

\subsubsection{AICC.}

For AICC assays, we used the same procedure as described for ADCC, but we added media or media/anti-CD20 instead of ch14.18/CHO antibody to a final volume $200 \mu 1$ per well.

In order to block the death receptors in AICC, we pre-incubated target cells with $1 \mu \mathrm{g}$ antiTRAIL-R2 and anti-CD95 for 1h on ice. To block Fc-receptors on expanded NK cells, we used human FcR Blocking reagent ( $10 \mu 1$ per $2 \times 10^{6}$ cells in $100 \mu 1$ FACS buffer). The mixture was incubated on ice for 10-15 min. Effector and target cells were washed twice to remove residual antibodies and then employed in an AICC assay as described above, in an E:T ratio of 2.5:1.

Cytotoxicity was calculated according to the following formulas: 
For CDC: \% cytotoxicity $=($ Experimental - Target Spontaneous $) /($ Target Maximum - Target Spontaneous)

For ADCC and AICC: \% cytotoxicity = (Experimental - Effector Spontaneous - Target spontaneous $) /$ (Target Maximum - Target Spontaneous)

\subsubsection{Granzyme B (GrB) and perforin ELISA.}

For measuring $\mathrm{GrB}$ and perforin release from PBMCs upon co-culture with fenretinide-treated NB cells, cells were incubated for 6 hours in a 24well plate at an E:T ratio of 20:1. We used $1 \times 10^{5} \mathrm{NB}$ cells in $250 \mu \mathrm{l}$ RPMI complete medium and accordingly $2 \times 10^{6}$ PBMCs (in $250 \mu \mathrm{l}$ ) in each well. To measure spontaneous GrB and perforin release by PBMCs we incubated PBMCs alone in the same volume that was used in the other wells $(500 \mu \mathrm{l})$. The ELISA was performed according to the manufacturer's protocol (Human Granzyme B and Human Perforin ELISA Kit). Briefly, on day 1 a high protein binding ELISA plate was coated with $100 \mu \mathrm{l} /$ well of anti-GrB or anti-perforin monoclonal antibody diluted to $1.5 \mu \mathrm{g} / \mathrm{ml}$ or $4 \mu \mathrm{g} / \mathrm{ml}$ in PBS. The plate was incubated overnight at $4^{\circ} \mathrm{C}$. On the next day, the plate was washed twice with $200 \mu 1 /$ well washing buffer $(0.05 \%$ Tween 20 in PBS) followed by blocking with $200 \mu \mathrm{l} /$ well of assay diluent (PBS containing $0.1 \% \mathrm{BSA}$ ) for $1 \mathrm{~h}$ at RT. Plate was washed 5 times with washing buffer. $100 \mu 1$ of standards diluted in assay diluent and $100 \mu 1$ of samples was added to each well and incubated for $2 \mathrm{~h}$ at RT. The plate was again washed 5 times with washing buffer followed by incubation with $100 \mu \mathrm{l} /$ well of biotinylated monoclonal antibody diluted to 0.5 $\mu \mathrm{g} / \mathrm{ml}$ in assay diluent for $1 \mathrm{~h}$ at RT. After washing the plate was incubated with $100 \mu 1 /$ well of streptavidin-HPR (1:1000 in assay diluent) for $1 \mathrm{~h}$ at RT. The plate was washed 5 times and $75 \mu 1 /$ well of TMB substrate reagent (Color Reagent A and Color Reagent B mixed in equal volumes) was added and incubated for 5-20 minutes in the dark, depending on color development. After a suitable developing time, $75 \mu \mathrm{l} /$ well of stop solution $\left(2 \mathrm{~N} \mathrm{H}_{2} \mathrm{SO}_{4}\right.$ ) was added and optical density (OD) was measured at $450 \mathrm{~nm}$ using a standard microplate reader.

Antibody-dependent $\mathrm{GrB}$ and perforin release was calculated by subtracting the spontaneous release from the experimental release values.

\subsubsection{Western Blot analysis.}

$5 \times 10^{5}$ CHLA-136 cells per well were plated in complete IMDM medium (3 ml) into flat-bottom 6well plates. Cells were exposed to 4-HPR, PPPP alone or in combination as described above. Cells were harvested, washed twice (PBS) and centrifuged. Pellets were lysed on ice with $200 \mu 1$ lysis buffer 
(RIPA buffer, $1 \mathrm{mM}$ sodium ortho-vanadate and $1 \mathrm{mM}$ sodium fluoride) for 15 minutes. After centrifugation $\left(12000 \mathrm{rpm}, 15\right.$ minutes, $\left.4^{\circ} \mathrm{C}\right)$ the supernatant was transferred to a new tube and protein concentration was determined using the Bio-Rad Protein Assay. Supernatants (40 $\mu \mathrm{g}$ of cell protein) were mixed with $4 \mathrm{X}$ SDS Sample Buffer and heated for $3 \mathrm{~min}$ at $96^{\circ} \mathrm{C}$ to denature the proteins. Proteins were resolved by electrophoresis on a $10-20 \%$ triethanolamine sodium dodecyl sulfate precast gel. Electrophoresis was performed at $80 \mathrm{~V}$ for first $15-20 \mathrm{~min}$ and at $120 \mathrm{~V}$ for $1.5-2 \mathrm{~h}$ using Dual Vertical Mini-gel system in SDS running buffer.

After electrophoresis the gel, containing resolved proteins, and four pieces of the blotting paper were incubated in transfer buffer for $5 \mathrm{~min}$. Polyvinylidene difluoride (PVDF) membrane was activated in $100 \%$ methanol for $5 \mathrm{~min}$, washed in double distilled water (dd $\mathrm{H} 2 \mathrm{O})$ and soaked into transfer buffer. The sandwich was assembled in the following order from anode to cathode: two pieces of blotting paper, PVDF membrane, gel, two pieces of blotting paper. The proteins were blotted onto the PVDF membrane at $30 \mathrm{~V}, 100 \mathrm{~mA}$ for $40 \mathrm{~min}$ by using the Owl HEP-3 Semi Dry Electroblotting System.

In order to block non-specific binding sites, the membrane was incubated in blocking buffer (5\% nonfat dry milk, $0.1 \%$ vol/vol Tween 20 in PBS) for $1.5 \mathrm{~h}$ at RT.

For detection of glucosylceramide synthase (GCS) the membrane was incubated over night at $4{ }^{\circ} \mathrm{C}$ with a monoclonal mouse anti-human GCS antibody (1:200) in blocking buffer. For detection, a secondary peroxidase-conjugated goat anti-mouse IgG1 antibody (1:2000) was used. The reaction was visualized using the enhanced chemiluminescence (ECL) detection system according to the manufacturer's protocol. As a control we employed a monoclonal mouse anti- $\beta$-actine antibody (diluted 1:1000), and a peroxidase-conjugated goat anti-mouse IgG1 (1:5000).

\subsubsection{Mouse xenograft experiments.}

Female NOD/SCID mice were obtained at 4 to 6 weeks of age from Charles River and maintained under specific pathogen-free conditions. Housing and treatment protocols were approved by the institutional animal care \& use committee (IACUC) of our institution.

\subsubsection{Tumor induction and treatment procedure.}

For tumor induction, CHLA-136 neuroblastoma cells were harvested, washed twice with IMDM medium without supplements, counted and resuspended in IMDM medium without adds to the final concentration of $1 \times 10^{7}$ cells $/ 100 \mu 1$. Cells were used for tumor induction only if their viability exceeded 
95\%, as determined by trypan blue staining. Shortly before injection, cell suspension was diluted 1:1 with Matrigel ${ }^{\mathrm{TM}}$ Basement Membrane Matrix, which was kept on ice during thawing and the following procedures. Mice were inoculated subcutaneously into the right flank with $200 \mu 1$ of IMDM medium (without supplements) and Matrigel mixture ( $=1 \times 10^{7}$ CHLA-136 tumor cells).

Tumors were measured every second day using a micro caliper and tumor volumes were calculated according to the formula: $1 / 2$ width $\mathrm{x}$ length $\mathrm{x}$ width. When tumors reached a volume of 150 $200 \mathrm{~mm}^{3}$ on average, mice were assigned to receive a daily dosage of 4-HPR. 4-HPR was applied by oral gavage as 4-HPR/LYM-X-SORB oral powder with a final concentration of $4-H P R ~ 240 \mathrm{mg} / \mathrm{kg} / \mathrm{d}$ mixed in sterile water. The control group was treated with $100 \mu 1$ PBS. Animals were sacrificed by carbon dioxide necrosis, when tumor volumes reached $1300 \mathrm{~mm}^{3}$. Tumors were extracted und processed for the following ex vivo assays.

\subsubsection{Ex vivo ADCC assay.}

To assess the effects of fenretinide on neuroblastoma cells in vivo, extracted tumors were cut into small fragments and mashed through a $70 \mu \mathrm{m}$ cell strainer into one well of a 6 well-plate containing $5 \mathrm{ml}$ IMDM complete medium using the rubber plunger end of a syringe. Suspended cells were transferred into a $50 \mathrm{ml}$ Falcon tube and washed twice with $10 \mathrm{ml}$ IMDM complete medium by centrifugation at $1250 \mathrm{rpm}$ for 5 minutes. In order to remove red blood cells, tumor cells were treated with $5 \mathrm{ml} \mathrm{ACK}$-lysis buffer $\left(0.15 \mathrm{M} \mathrm{NH}_{4} \mathrm{Cl}, 10 \mathrm{mM} \mathrm{KHCO}_{3}, 0.1 \mathrm{mM}\right.$ EDTA in distilled water) for 5 min at RT followed by two washes with IMDM complete medium. To remove dead cells, we performed density gradient centrifugation using Ficoll-Paque ${ }^{\mathrm{TM}}$ PLUS (400× $\mathrm{g}$ without brake for 30 min at $4^{\circ} \mathrm{C}$ ). Living cells were collected from the interphase and washed twice in complete IMDM medium, counted and employed in an ADCC assay as described above.

\subsubsection{Analysis of tumor-infiltrating NK cells.}

To determine whether 4-HPR treatment has an effect on the amount of tumor-infiltrating NK cells, we isolated all live cells from tumors as described above. $1 \times 10^{6}$ cells were stained with $1 \mu 1$ of an anti-mouse NK1.1 FITC-conjugated antibody in $100 \mu 1$ FACS-buffer for 45 minutes. As an isotype control we used a FITC-labeled mouse IgG2A, K isotype antibody. After incubation with antibody, cells were washed twice, counterstained with DAPI as described above and analyzed by flow cytometry. 


\subsubsection{Statistical analysis.}

All experiments were verified at least three times. Data are expressed as means \pm SD. Data were analyzed using GraphPad Prism software and statistical analysis was performed using Student's t test. Differences were considered significant at a $\mathrm{P}$ value of $<0.05\left(^{*}\right)$ and highly significant at $\mathrm{P}$ values $<0.01(* *)$ or $<0.005(* * *)$. 
Results

\section{Results.}

3.1. GD2 expression of 4-HPR-resistant human NB cells increases upon treatment with 4HPR.

Since fenretinide induces the accumulation of (dihydro)ceramide [66], which is a ganglioside precursor, we analyzed the expression of the ganglioside GD2 upon treatment with 4-HPR in 4HPR-resistant NB cells by using flow cytometry. We found an increase of GD2 cell surface expression in all 6 human 4-HPR-resistant cell lines (CHLA-136, CHLA-172, SK-N-BE(2), CHLA-79, CHLA-15 and CHLA-20) (Fig. 3.1 A). From the percentage of GD2 positive cells and mean fluorescence we calculated the GD2 binding index for basal cell surface expression and for expression after treatment with 4-HPR. The average increase of the GD2 binding index in all six cell lines, compared to vehicle-treated controls, was calculated from 5 independent experiments (Fig. $3.1 \mathrm{~B}$ ). Interestingly, in cell lines with a more heterogeneous basal expression of GD2 (CHLA-136, SK-N-BE(2)), 4-HPR induced an increase in the percentage of GD2-positive cells (data not shown) and in the mean fluorescence intensity, resulting in a 1.5 to 1.8 -fold increase of the average GD2 binding index, respectively. In the case of cell lines with high and homogeneous expression of GD2 (CHLA-15 and CHLA-20, basal expression of GD2 was 92-95\%), treatment with 4-HPR induced a 1.2 fold increase in the GD2 binding index, which is mostly dependent on an increase in the mean fluorescence. Thus, NB cell lines having the lowest basal levels of GD2 expression demonstrated the greatest 4-HPR-mediated increase in GD2 expression.

Fig 3.1: GD2 expression of 4-HPR resistant human NB cells increases upon treatment with 4-HPR.

A)



GD2 expression was analyzed in 4-HPR resistant NB cells after exposure to $10 \mu \mathrm{M}$ 4-HPR (2.5 $\mu \mathrm{M}$ for CHLA-15) for $48 \mathrm{~h}$ as described in Material and Methods. Cells were stained with ch14.18/CHO $(1 \mu \mathrm{g})$ and results were compared to rituximab $(1 \mu \mathrm{g})$ as isotype control. A) Representative histograms show results with ch14.18/CHO in vehicle-treated cells (dotted black line, tinted gray curve), in 4-HPR-treated cells (solid black line) and an isotype control in 4-HPR-treated cells (solid black line, filled black curve). 
B)



B) GD2 binding index (BI) was calculated according to the formula: (mean fluorescence $\mathrm{x} \% \mathrm{GD} 2$ positive cells)/100. Results are presented as fold increase of GD2 BI of 4-HPR treated cells from vehicle control. Horizontal line indicates control expression. Data represent the mean increase and SD of five independent experiments. P-values were calculated using the Student's t test $(\mathrm{p}<0.05(*))$.

\subsection{Fenretinide increases ch14.18-mediated effector mechanisms.}

\subsubsection{4-HPR enhances ch14.18/CHO-mediated CDC of 4-HPR-resistant human NB cells.}

Complement-dependent cytotoxicity (CDC) was analyzed after 4-HPR treatment using five 4-HPR-resistant NB cell lines (CHLA-136, CHLA-172, SK-N-BE(2), CHLA-79 and CHLA-20). Cells were treated with $5 \mu \mathrm{M}$ 4-HPR for $48 \mathrm{~h}$, resulting in an increase of CDC with ch14.18/CHO of up to $45 \%$ (CHLA-136, CHLA-172 and SK-N-BE(2)) and up to 25\% (CHLA-79, CHLA-20) compared to vehicle controls (Fig. 3.2.1), while isotype control rituximab did not elicit a CDC response at all. Interestingly, the level of ch14.18/CHO-mediated CDC correlated with the GD2 binding index (Fig. 3.1): CHLA-136, CHLA-172 and SK-N-BE(2) showed the highest increase in CDC compared to the other cell lines tested, i.e. CHLA-20 and CHLA-79. We were able to confirm this result with serum from another donor as complement source and $1 \mu \mathrm{g} / \mathrm{ml} \mathrm{ch} 14.18 / \mathrm{CHO}$ (data not shown).

Fig. 3.2.1: Fenretinide treatment enhances ch14.18/CHO-mediated CDC towards 4-HPR-resistant human NB cell lines.



CDC assay was performed with $10 \%$ of human serum in the presence of ch14.18/CHO or isotype control rituximab $(10 \mu \mathrm{g} / \mathrm{ml}$ each) and NB cells previously treated with $5 \mu \mathrm{M} 4-\mathrm{HPR}$ for $48 \mathrm{~h}$. Each bar represents the mean value for eight replicates. The results from one representative experiment out of three independent experiments are presented as mean \% CDC \pm SD. Differences of ch14.18/CHO-mediated CDC and controls were statistically significant $(* * * \mathrm{p}<0.001, * * \mathrm{p}<0.01$, Student's t test). 


\subsubsection{4-HPR enhances ch14.18/CHO-mediated ADCC of 4-HPR-resistant human NB cells by} peripheral blood mononuclear cells.

Next, we determined whether the increase of GD2 expression would also lead to an enhanced ch14.18/CHO-mediated ADCC. First, overall cytotoxicity with ch14.18/CHO was analyzed with PBMCs from one healthy donor and cell lines CHLA-20, CHLA-172, SK-N-BE(2) and CHLA-79 treated with 4-HPR $(10 \mu \mathrm{M})$. All cell lines were lysed more effectively after 4-HPR treatment (Fig. 3.2.2 A). Importantly, similar effects were observed when we determined the ADCC by PBMCs obtained from four healthy donors towards CHLA-20 cells that were treated with 4HPR $(10 \mu \mathrm{M})$ for $48 \mathrm{~h}$. All four donor PBMCs showed an increase in lytic activity towards CHLA20 after treatment with 4-HPR (Fig. 3.2.2 B).

Fig. 3.2.2: Fenretinide treatment enhances ch14.18/CHO-mediated ADCC towards 4-HPR-resistant human NB cell lines.

A)



B)



ADCC with healthy donor PBMCs was analyzed at an E:T ratio of 25:1 in the presence of ch14.18/CHO antibody $(1 \mu \mathrm{g} / \mathrm{ml})$. A) Varying human NB cell lines were exposed to vehicle (black bar) or $10 \mu \mathrm{M}$ 4-HPR (gray bar) for 48h and then used in an ADCC assay with PBMCs from donor 1. B) Varying donors were used as effector cells source after treatment of CHLA-20 with vehicle (black bar) or 10 $\mu \mathrm{M} 4$-HPR (gray bar). Each bar represents the mean value for 8 replicates. Results from one representative experiment out of three independent experiments are presented as \% cell lysis by PBMCs \pm SD. Differential findings between 4HPR treated cells and controls were statistically significant $\left(* * * \mathrm{p}<0.001, * * \mathrm{p}<0.01,{ }^{*} \mathrm{p}<0.05\right.$, Student's $\mathrm{t}$ test).

In order to assess the overall ability of 4-HPR to increase cytotoxicity of PBMCs from different donors we pooled our data for 4 donors from 3 experiments, respectively, and calculated the \% increase of cytotoxicity towards 4-HPR treated CHLA-20 cells compared to vehicle treated CHLA-20, revealing an average increase in cytotoxicity of $102 \%( \pm 48 \% \mathrm{SD}$, data not shown). 
3.3. Fenretinide treatment enhances AICC and ch14.18/CHO-mediated ADCC by purified NK cells towards 4-HPR-resistant human NB cell lines.

We wanted to confirm the results obtained with different PBMCs with a purified NK cell population from one healthy donor. For this purpose, we evaluated the cytotoxicity of expanded NK cells with ch14.18/CHO (ADCC) and without antibody (AICC) in six NB cell lines (CHLA-136, CHLA-172, SK-N-BE(2), CHLA-79, CHLA-15, CHLA-20) after exposure to $10 \mu \mathrm{M} 4-\mathrm{HPR}$ (2.5 $\mu \mathrm{M}$ 4-HPR for CHLA-15) for 48 hours. Since rituximab did not show any specific activity in CDC assays, and rituximab-mediated ADCC of NK cells and PBMCs was identical to controls without any antibody in preliminary experiments (data not shown), we only employed no-antibody controls in the following assays to determine the effect of 4-HPR treatment on ADCC/AICC.

The expanded NK effector cells showed a significantly higher overall lytic activity (ADCC+AICC) towards all fenretinide-treated NB cells compared to vehicle controls with an enhanced GD2-specific ADCC (gray part of the bars) and an increase in AICC (black part of the bars) (Fig. 3.3).

Fig. 3.3: Fenretinide treatment enhances AICC and ch14.18/CHO-mediated ADCC by purified NK cells towards 4-HPR-resistant human NB cell lines.



Overall cytotoxicity (AICC+ADCC) was analyzed with expanded NK cells and human NB cells that were treated with $10 \mu \mathrm{M}$ 4-HPR for $48 \mathrm{~h}$ at an E:T ratio of 5:1 in the presence (ADCC, gray part of stacked bar) or absence (AICC, black part of stacked bar) of ch14.18/CHO antibody $(1 \mu \mathrm{g} / \mathrm{ml})$. Each bar represents the mean value for 8 replicates. Results are presented as \% cytotoxicity \pm SD (from one representative experiment out of three independent experiments). Differences in ADCC and AICC with and without 4-HPR treatment were statistically significant $\left(* * * \mathrm{p}<0.001, * * \mathrm{p}<0.01,{ }^{*} \mathrm{p}<0.05\right.$, Student's $\mathrm{t}$ test).

In all cell lines the AICC response was markedly increased. The increase in GD2-specific ADCC was more pronounced in CHLA-136, CHLA-172 and SK-N-BE(2), while in CHLA-79, CHLA-15 and CHLA-20 ADCC mediated by ch14.18/CHO was only slightly higher upon treatment with 4-HPR compared to vehicle-treated cells, correlating with the limited effect of 4HPR on GD2 expression in these cells and similar to observations in CDC experiments. 
Importantly, the absence of AICC by NK cells towards untreated SK-N-BE(2) was reversed by treatment with 4-HPR, again indicating that there is a second mechanism involved in sensitization of NB cells to NK cell lysis by 4-HPR treatment.

\subsection{Effect of 4-HPR treatment on Fas and TRAIL-R2 expression on neuroblastoma cells.}

Since 4-HPR treatment increased susceptibility of human NB cells to effector cell killing by AICC, we examined the expression of death receptor (DR) molecules on our human NB cell lines. We demonstrate for 5 human NB cell lines (CHLA-136, CHLA-172, SK-N-BE(2), CHLA-79, and CHLA-15) a 4-HPR-mediated increase of Fas and TRAIL-R2 expression compared to vehicletreated cells. All cell lines tested in our panel were negative for TRAIL-R1 (data not shown). Fas expression was relatively low in all cell lines and was not detectable in CHLA-172 before or after treatment, but could be enhanced >3-fold in CHLA-15 and CHLA-136 cells after 4-HPR treatment (Fig. 3.4, left panel). TRAIL-R2 expression increased upon 4-HPR treatment up to 15-fold in all cell lines tested (Fig. 3.4, right panel).

Fig. 3.4: Effect of 4-HPR treatment on Fas and TRAIL-R2 expression on neuroblastoma cells.



Fas and TRAIL-R2 expression on NB cells was analyzed by flow cytometry as described in Material and Methods. Fas and TRAIL-R2 binding indices were calculated and results are presented as fold increase of BI of 4-HPR treated cells compared to vehicle control. Horizontal line indicates control expression. Data represent the mean increase and SD from five independent experiments.

\subsection{Inhibition of AICC after DR-blocking.}

In order to determine a functional role for DR expression after 4-HPR treatment in AICC we blocked the respective DRs during an AICC assay by using non-apoptosis inducing blocking antibodies for Fas and TRAIL-R2. AICC was analyzed with CHLA-136 cells as a target and expanded human NK effector cells, which were pre-treated with FcR block prior to the assay in order to prevent a Fas-/TRAIL-R2 antibody-mediated ADCC response. Interestingly, Fas blocking did not influence the increased AICC of expanded NK cells towards CHLA-136 after 4-HPR 
treatment at all (Fig. 3.5). In contrast, TRAIL-R2 blocking resulted in a significant decrease of AICC from $42 \%$ to $32 \%$ suggesting a role for a 4-HPR-stimulated TRAIL/TRAIL-R2 pathway as a mechanism for the increased AICC (Fig. 3.5).

Fig. 3.5: Inhibition of AICC after DR-blocking.

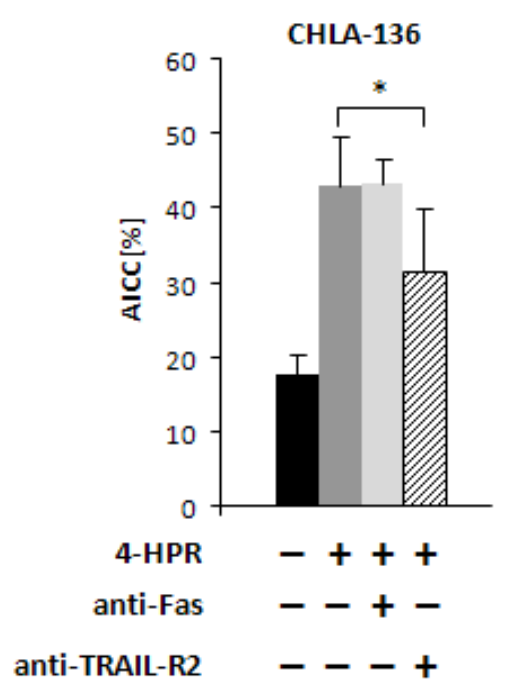

NB cells CHLA-136 were exposed to $5 \mu \mathrm{M} 4$-HPR or vehicle for $48 \mathrm{~h}$. After treatment, cells were harvested and incubated with non-apoptosis-inducing anti-TRAIL-R2 and anti-CD95 (Fas) antibodies for 1h on ice ( $1 \mu \mathrm{g}$ each). The lytic activity of NK cells was assessed at E:T ratio 2.5:1. Each bar represents the mean value for 8 replicates. Results are presented as \% cell lysis by NK cells of 4-HPR treated cells (dark gray column) compared to vehicle treated cells (black column) with Fas blocking (light gray column) or TRAIL-R2 blocking (hatched column) from one representative experiment out of three independent experiments \pm SD. The difference between TRAIL-R2 blocking and AICC in 4-HPR-treated cells was statistically significant (* $\mathrm{p}<0.05$, Student's $t$ test).

\subsection{Granzyme B and perforin production by PBMCs in response to activation with fenretinide-treated NB cells.}

Since effector cells (PBMCs and expanded NK cells) showed a significantly higher overall lytic activity towards fenretinide-treated NB cells compared to the vehicle control, we examined Granzyme B $(\mathrm{GrB})$ and perforin production by PBMCs in response to activation with NB cells. For this purpose, NB cells (SK-N-BE(2), CHLA-20, CHLA-172, CHLA-136) treated with 10 $\mu \mathrm{M} 4-$ HPR for $48 \mathrm{~h}$ were incubated with PBMCs from 2 different donors and the concentration of the effector molecules GrB (Fig. 3.6. A) and perforin (Fig. 3.6. B) was measured in the supernatant. 4HPR treatment of NB cells resulted in an increase of $\mathrm{GrB}$ and perforin production (up to 2.5 fold and up to 2 fold increase, respectively). These data revealed the correlation between enhanced cytotoxic activity of PBMCs and increased GrB and perforin release and indicate that the increased susceptibility of human NB cells to effector cell after 4-HPR treatment is mediated by an increased production of lytic components (GrB, Perforin) by effector cells. 
Fig. 3.6: Granzyme B and perforin production by PBMCs.

A)



B)

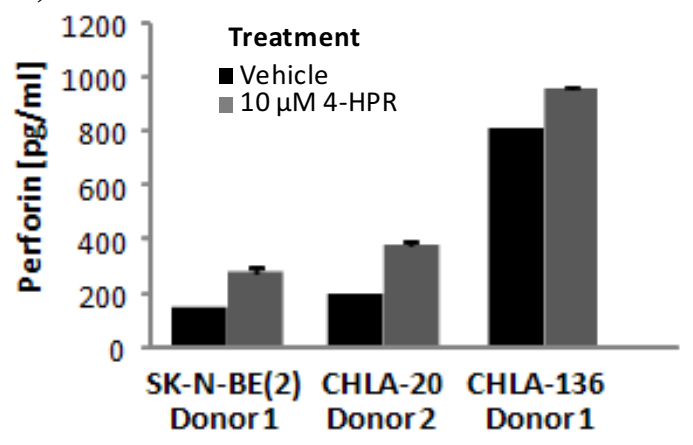

Granzyme B and perforin production of PBMCs upon co-incubation with NB cells was quantified by ELISA. A) Granzyme B production of PBMCs. Results are presented as $\mathrm{GrB}$ concentration in $\mathrm{pg} / \mathrm{ml} \pm \mathrm{SD}$. (B) Perforin production of PBMCs. Results are presented as perforin concentration in $\mathrm{pg} / \mathrm{ml} \pm \mathrm{SD}$.

\subsection{Disruption of ganglioside synthesis leads to an abrogation of 4-HPR-mediated increase in ch14.18-dependent ADCC and CDC.}

\subsubsection{Effect of 4-HPR and PPPP on GCS expression.}

Since the drug-resistant phenotype in cancer cells is often associated with an increase in ceramide glycosylation [72,73,77], we determined whether 4-HPR resistance in CHLA-136 cell line is correlated with an over expression of glucosylceramide synthase (GCS). As shown in Fig. 3.7.1, protein expression of GCS showed an apparent increase in 4-HPR-treated CHLA-136 cells relative to vehicle-treated controls, while exposure to PPPP during 4-HPR exposure decreased GCS protein expression.

Fig. 3.7.1: Effect of 4-HPR and PPPP on GCS expression.

\section{CHLA-136}

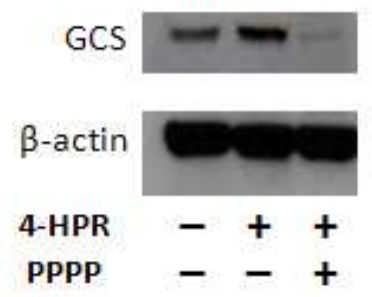

CHLA-136 cells were treated with vehicle or $5 \mu \mathrm{M} 4-\mathrm{HPR}$ or $1 \mu \mathrm{M}$ PPPP/5 $\mu \mathrm{M} 4$-HPR for $48 \mathrm{~h}$ and then used to prepare lysates for Western blot analysis to detect GCS (44 kDa). $\beta$-actin was used as a control for equal protein loading.

\subsubsection{Effect of the inhibition of GCS with PPPP on GD2 expression.}

We wanted to test the hypothesis that a specific inhibition of GCS with PPPP will decrease the 4-HPR-enhanced cell surface density of GD2 on NB tumor cells. To investigate this hypothesis, three cell lines (CHLA-136, SK-N-BE(2) and CHLA-20), were treated with PPPP and 4-HPR as described in Material and Methods and levels of cell surface GD2 were assessed by flow cytometry. 
Cells treated with PPPP clearly showed lower GD2 expression compared to cells that did not receive the inhibitor (Fig. 3.7.2), visible by a decrease in fluorescence intensity (light grey curve)

Fig. 3.7 .2: Effect of 4-HPR and PPPP on GD2 expression.

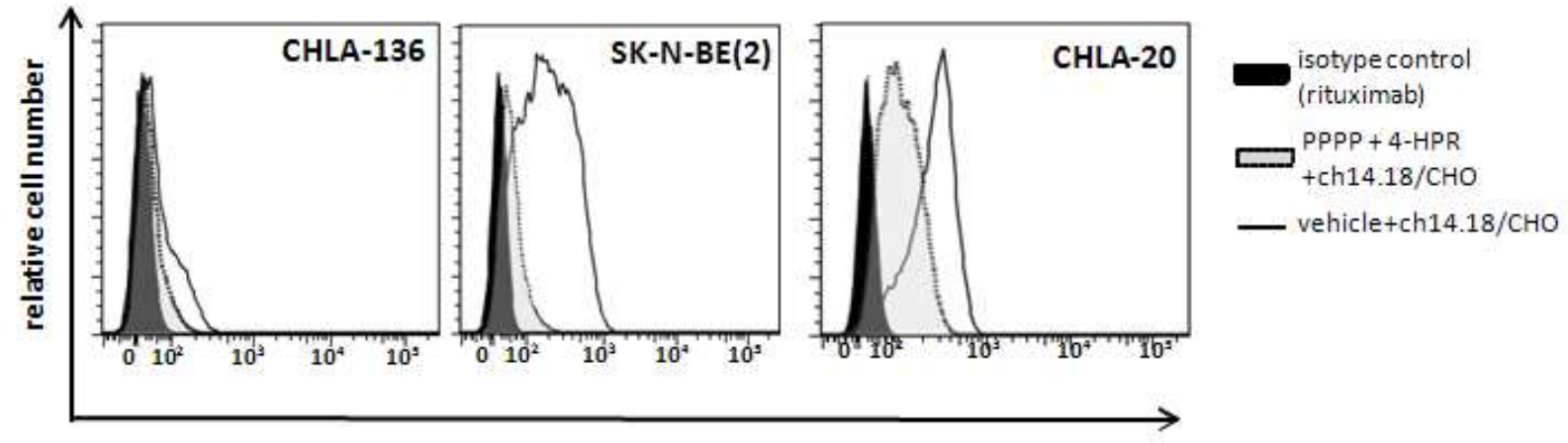

GD2

PPPP-mediated inhibition of GD2 expression is shown in representative histograms from three independent experiments with vehicle (solid black line), PPPP plus 4-HPR (dotted black line, tinted gray curve) and an isotype control (solid black line, filled black curve).

\subsubsection{Effect of the inhibition of GCS with PPPP on 4-HPR-mediated increase of ch14.18/CHO-dependent ADCC and CDC.}

In order to analyze whether disrupting of ganglioside synthesis will affect antibodymediated cytotoxicity, we performed CDC and ADCC assays. Indeed, as shown in Fig. 3.7.3 A, inhibition of GCS resulted in a highly significant decrease of CDC when cells were treated with 4HPR and PPPP, thereby completely abrogating the enhancing effect of 4-HPR treatment that we saw before (Fig. 3.1.). Interestingly, when we performed an ADCC/AICC assay with CHLA-136 and 4-HPR/PPPP we found that the 4-HPR-mediated increase of GD2-specific lysis (ADCC) can be abrogated by using PPPP (light grey part of stacked bar graph). Importantly, the AICC response remained unaffected (Fig. 3.6.3 B, black part of stacked bar graph). Our data suggest that GCS is at least partially responsible for the increase of GD2-specific ADCC and CDC towards NB cells after 4-HPR treatment by contributing to an increased GD2 expression, although we cannot rule out that other enzymes from the ganglioside synthesis pathway are involved. Therefore, disrupting ganglioside synthesis by using PPPP leads to a decreased GD2 level and a decreased CDC and GD2-specific lysis in ADCC, indicating a crucial role for GD2 expression as a mechanism for 4HPR-mediated sensitization of NB for ch14.18/CHO-mediated immunotherapy. 
Fig. 3.7.3: Inhibition of GD2 expression reverses the 4-HPR-mediated increase in ch14.18/CHOdependent ADCC and CDC.

A)



B)

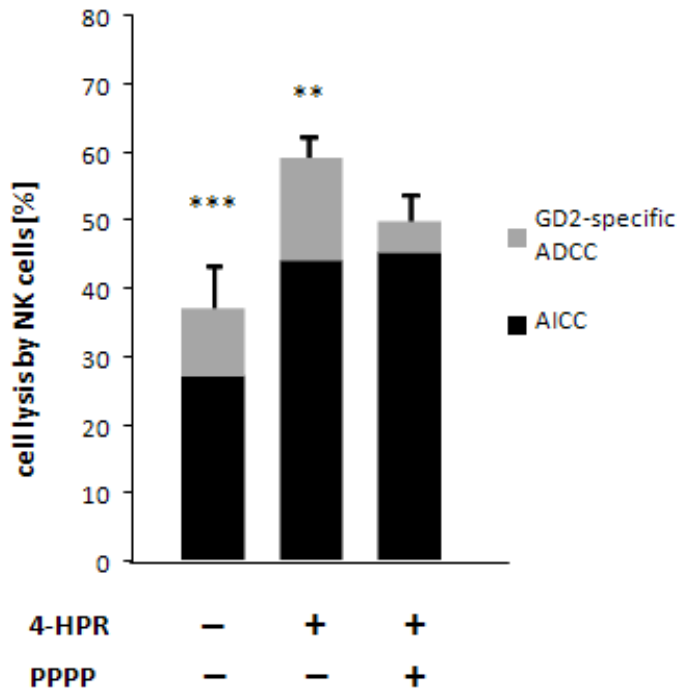

A) CDC was analyzed with $10 \%$ human serum and NB target cells treated with 4-HPR $(5 \mu \mathrm{M})$ or 4HPR/PPPP $(5 \mu \mathrm{M} / 1 \mu \mathrm{M})$ in the presence of ch14.18/CHO or rituximab control $(10 \mu \mathrm{g} / \mathrm{ml})$. Each bar represents the mean value for 8 replicates. Results from one representative experiment out of three independent experiments are presented as \% of cell lysis of target cells \pm SD. Differences in CDC with and without 4HPR treatment were statistically significant (*** $\mathrm{p}<0.001$, ** $\mathrm{p}<0.01$, Student's $\mathrm{t}$ test). B) Human NB cell line CHLA-136 was treated with $1 \mu \mathrm{M}$ PPPP/ $5 \mu \mathrm{M}$ 4-HPR (right column), vehicle (left column) or $5 \mu \mathrm{M} 4$ HPR alone for $48 \mathrm{~h}$ (middle column). Expanded NK cells were employed as effector cells at an E:T ratio of $5: 1$ in the absence or presence of ch14.18/CHO antibody $(1 \mu \mathrm{g} / \mathrm{ml})$. Each bar represents the mean value for 8 replicates. Results from one representative experiment out of three independent experiments are presented as $\%$ AICC by NK cells (black part of stacked bars) and ch14.18/CHO-mediated lysis (gray part of stacked bars) \pm SD. The difference in overall cytotoxicity between 4-HPR/PPPP-treated and 4-HPR-treated cells was statistically significant $(* * * \mathrm{p}<0.001, * * \mathrm{p}<0.01$ ), as well as the difference in GD2-specific ADCC between groups $(* \mathrm{p}<0.05$, Student's t test; not indicated in the figure).

\subsection{Effect of 4-HPR treatment on NK cell mediated killing in neuroblastoma xenografts.}

\subsubsection{Effect of 4-HPR treatment on GD2, Fas and TRAIL-R2 expression on}

neuroblastoma cells in vivo.

To assess whether the observed in vitro effects of fenretinide on NB cells also occurred in vivo, Fox Chase SCID mice (CB17/Icr-Prkdc scid/IcrIcoCrl) with established, palpable CHLA-136 NB xenografts $\left(200 \mathrm{~mm}^{3}\right)$ were assigned to treatment with $240 \mathrm{mg} / \mathrm{kg}$ 4-HPR or sterile water (diluent). When tumors reached a volume of $1300 \mathrm{~mm}^{3}$ mice were terminated, tumor cells were isolated and analyzed for GD2, Fas and TRAIL-R2 expression by flow cytometry and binding indices were calculated. Tumors of mice treated with 4-HPR showed a significantly increased GD2 binding index compared to tumors of control mice (Fig. 3.8.1). Furthermore, both Fas and TRAILR2 binding indices were increased in 4-HPR-treated tumors compared to control tumors, 1.6 fold for Fas and 1.25 fold for TRAIL-R2 (Fig. 3.8.1). 


\section{Results}

Fig. 3.8.1: Effect of 4-HPR treatment on GD2, Fas and TRAIL-R2 expression on neuroblastoma cells in vivo.

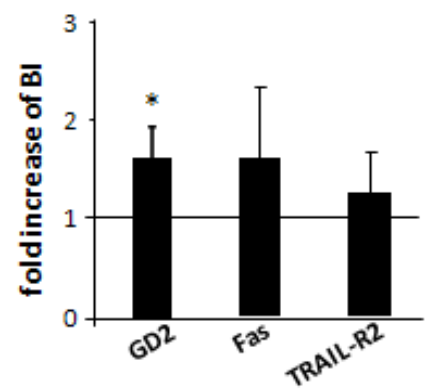

GD2, Fas and TRAIL-R2 BI were calculated and expressed as mean fold increase of BI of tumors from six 4-HPR treated animals compared to controls \pm SD. Horizontal line indicates control. The increase of the GD2 BI after 4-HPR treatment was statistically significant $(* \mathrm{p}<0.05$, Student's $\mathrm{t}$ test)

\subsubsection{Fenretinide treatment enhances AICC and ch14.18/CHO-mediated ADCC by purified NK cells towards 4-HPR-resistant human NB CHLA-136 cell line ex vivo.}

Next we tested whether 4-HPR-mediated increase of GD2 and DR expression in vivo also translated into effective cell killing by effector cells. Isolated tumor cells from 4-HPR treated mice were tested ex vivo in a cytotoxicity assay with expanded human NK cells as effector cells. Both AICC and GD2-specific ADCC by NK cells were increased after treatment of mice with 4-HPR in vivo (Fig. 3.8.2), resulting in a significantly enhanced overall cytotoxicity by NK cells. Interestingly, the GD2-specific ADCC of NB cells isolated from primary tumors (gray part of stacked bars) was much higher than the AICC response (black part of stacked bars), which was reversed in our in vitro experiments (e.g. Fig. 3.3.). Indeed, CHLA-136 cells isolated from primary tumors showed a more homogenous and higher GD2 expression compared to CHLA-136 cells grown in vitro (data not shown).

Fig. 3.8.2: Effect of 4-HPR treatment on NK cell mediated killing in neuroblastoma xenografts.



ADCC was analyzed with NK cells as effector cells and target cells isolated from explanted CHLA-136 tumors at an E:T ratio of 5:1 in the presence (ADCC) or absence (AICC) of ch14.18/CHO $(1 \mu \mathrm{g} / \mathrm{ml})$. Results are presented as mean \%AICC (black part of stacked bars) and ADCC (gray part of stacked bars) of NK cells for 6 control tumors and 6 tumors of 4-HPR treated mice ( 8 replicates each). The difference in overall cytotoxicity (ADCC+AICC) between vehicle-treated and 4-HPR-treated tumors was statistically significant $(* \mathrm{p}<0.05$, Student's t test). 


\section{Results}

\subsubsection{Treatment with 4-HPR mediates increased tumor infiltration by NK cells in vivo.}

As NK cells play a crucial role in ADCC, we wanted to find out whether treatment with 4HPR in vivo would influence the number of tumor-infiltrating NK cells. We evaluated the amount of infiltrating NK cells by analyzing the percentage of NK1.1+ cells in the whole tumor-derived cell population with flow cytometry. Interestingly, tumors from 4-HPR-treated mice showed a significantly higher percentage of tumor infiltrating NK cells compared to control tumors (representative dot blots are shown in Fig. 3.8.3 A) resulting in a 6-fold increase over control tumors (Fig. 3.8.3 B, p=0.002).

Fig. 3.8.3: Treatment with 4-HPR increases amount of tumor-infiltrating NK cells in vivo.

A)



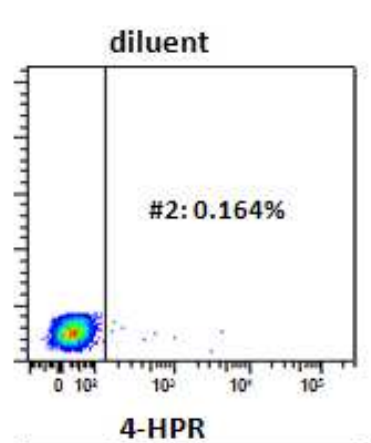



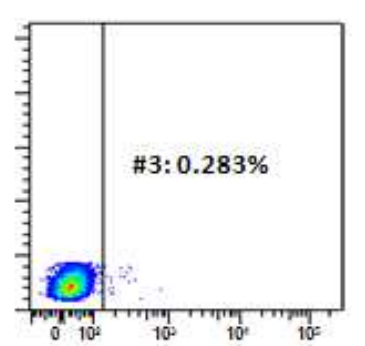

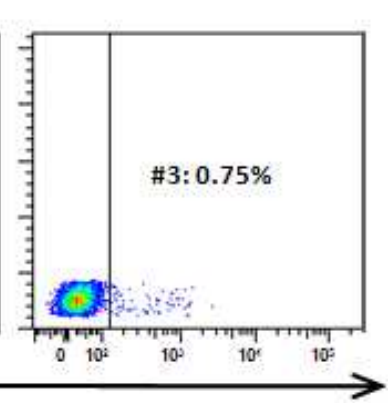

B)



\section{NK1.1}

A) Tumor-infiltrating NK cells after 4-HPR treatment were analyzed by flow cytometry. Representative dot blots are shown for diluent controls and 4-HPR-treated tumors (3 mice, respectively); isotype controls using FITC-labeled mouse IgG2A were subtracted. B) Fold increase of tumor-infiltrating NK cells in 4-HPRtreated tumors compared to controls was calculated from 6 mice of each group. Results are presented as fold increase of infiltrating NK cells in 4-HPR tumors compared to vehicle controls. Horizontal line indicates control. Difference between infiltrating NK cells in 4-HPR treated mice was statistically significant from vehicle-treated mice $(* * \mathrm{p}<0.01$, Student's $t$ test). 


\section{Discussion.}

Discussion

More than $50 \%$ of the patients with stage 4 neuroblastoma initially present with disseminated metastasis to distant organ sites, predominantly to the bone marrow, making effective treatment for this disease most challenging. Despite drastic therapeutic interventions with radiotherapy and/or high-dose chemotherapy, followed by allogeneic or autologous bone marrow transplantation, prognosis for high-risk NB patients remains poor with a five-year event-free survival rate of only $\sim 40 \%$ [4].

With current standard therapy most patients with high-risk disease achieve a complete remission, but a failure to eliminate minimal residual disease (MRD) often leads to relapse [75]. Unfortunately, relapsed tumors often do not respond to chemotherapy, due to the development of multi-drug resistance (MDR) [76]. Thus, the major problem in treatment of high-risk neuroblastoma is the elimination of chemotherapy-refractory MRD, emphasizing the need for the development of new and powerful treatment approaches.

The occurrence of chemotherapy-refractory disease in patients, whose tumors initially respond to chemotherapy, suggests an in vivo selection of drug-resistant tumor cells during therapy [76]. One strategy to treat MRD is to restore sensitivity to chemotherapeutic drugs. It has been recently reported, that a MDR phenotype is often associated with aberrant ceramide metabolism [77]. In this context, TNF- $\alpha$-resistant MCF7 breast cancer cells have been characterized by the inability of their neutral or acidic sphingomyelinases to generate ceramide [78]. Furthermore, in order to prevent ceramide accumulation and ceramide induced apoptosis, MDR tumor cells often exhibit an increased activity and/or expression of enzymes involved in ceramide clearance such as sphingosine kinase (converts sphingosine into sphingosine-1-phosphate, S1P)), sphingomyelin synthase (converts ceramide into sphingomyelin) and glucosylceramide synthase (GCS), which catalyzes the glycosylation of ceramide leading to the formation of glucosylceramide $[70,71,72]$. Therefore, the use of specific inhibitors of enzymes, which are involved in ceramide clearance, can sensitize MDR cells towards chemotherapy. It has been demonstrated in breast and in prostate cancer, that treatment of MDR cancer cells with either inhibitors of GCS or inhibitors of S1P restored sensitivity to chemotherapeutic agents $[71,77,79]$.

A promising alternative for the treatment of MRD is immunotherapy. Recently, it has been reported that the addition of the anti-GD2 antibody ch14.18/SP2/0, combined with rIL-2 and GMCSF, to standard therapy provides a clinical benefit with a $20 \%$ improvement in the 2-year prevention of relapse for children with high-risk neuroblastoma [52]. The primary mechanism of action of the anti-GD2 antibody is the induction of ADCC. However, effector cells in cancer patients have shown lack of function due to immune suppression from metastatic cancer and/or chemotherapy [91]. Antibody immunotherapy in NB can be improved by stimulating effector cells with cytokines [41] or by using other stimulators of the innate immune system, such as $\beta$-glucan. $\beta$ - 
glucan is a glucose polymer that can induce TNF- $\alpha$ secretion and ADCC by NK cells, monocytes and neutrophils [92]. All co-stimulatory strategies in NB immunotherapy so far have focused on the "effector side" of the immune response.

In this work, we were able to demonstrate for the first time that sensitization of the "target cell" towards antibody-mediated effects like ADCC and CDC provides a new strategy to further improve anti-NB immunotherapy. It is noteworthy that we were able to induce this effect with nontoxic concentrations of fenretinide in tumor cells that were highly multi-drug or partially drug resistant.

4-HPR treatment is known to induce an increase of gangliosides on 4-HPR-resistant ovarian cancer [73] and SH-SY5Y cells [69]. We expanded this attempt to multi-drug or partially resistant NB cells and show that 4-HPR induced an increase of GD2 expression. Furthermore, we were able to demonstrate that this effect translates into an increased ch14.18-mediated cytotoxicity by effector cells (ADCC) and complement (CDC) (Fig. 3.2.1 and 3.2.2), the primary mechanisms involved in antibody immunotherapy of neuroblastoma. Importantly, 4-HPR treatment had an enhancing effect on ADCC and CDC at two 4-HPR concentrations (5 and $10 \mu \mathrm{M}$ ) that are pharmacologically relevant in neuroblastoma patient sera [81], providing a broader range of effective concentrations.

We observed that 4-HPR treatment of target cells resulted in an enhanced AICC of effector cells (Fig. 3.3), a mechanism partly depending on NK cell-mediated DR-induced apoptosis. Similar to the previously reported effect of 4-HPR on increasing DR expression in colon cancer [82] and Ewing sarcoma cell lines [74], we observed an increase of Fas and TRAIL-R2 expression on NB cells (Fig. 3.4). Differential findings in this respect in ovarian cancer cells may relate to the low concentration of 4-HPR $(1 \mu \mathrm{M})$ used for the experiments [93]. The mechanism of increased AICC by 4-HPR-treatment in our study was not dependent on Fas, but partially mediated by TRAIL-R2, which is consistent with our findings that in all NB cell lines tested TRAIL-R2 expression was much higher than Fas expression. However, the merely partial inhibition of AICC after TRAIL-R2 blocking (Fig. 3.5) indicates that another mechanism is involved that ultimately alters the sensitivity of the tumor cells to NK cell-mediated lysis. Possible candidate molecules can be the ligands for activating receptors NKG2D of NK cells-MICA/B or ULBPs. Recently, it has been shown that retinoic acid (RA) up-regulated expression of MICA/B in human hepatocellular carcinoma cells [83]. The involvement of activating ligands in the enhanced immune response towards 4-HPR treated NB cells is further supported by the fact that PBMCs produce higher levels of GrB and perforin upon co-incubation with 4-HPR treated tumor cells. If death receptors were the only molecules involved, GrB and perforin levels should not be affected. Moreover, retinoids are known to increase inter-cellular adhesion molecule 1 (ICAM-1) expression in NB cells [84], which is crucial for the interaction with immune effector cells. This together with an increased GD2 antigen 
expression and a resulting enhanced ADCC makes a combination of 4-HPR and anti-GD2 immunotherapy very attractive.

It was shown previously that a combination of fenretinide, as a ceramide inducer, and inhibitors of the ceramide glycosylation pathway, such as PPMP, resulted in a synergistic cytotoxicity in cancer cells [78]. However, when we inhibited GCS by using the GCS inhibitor PPPP we found a down regulation of the ch14.18-target antigen GD2 resulting in a nearly complete abrogation of the 4-HPR-mediated increase of GD2-dependent cytotoxicity of effector cells and complement (Fig. 3.7.3). Our data indicate that GCS is at least partially responsible for the increase of GD2-specific ADCC and CDC towards NB cells after 4-HPR treatment by contributing to an increased GD2 expression. Thus, while combining 4-HPR with a GCS inhibitor may be advantageous in terms of cytotoxicity, our data would suggest that combinations of 4-HPR and antiGD2 immunotherapy should not include a GCS inhibitor.

Importantly, we could confirm sensitization of human NB cells by 4-HPR for lysis by immune effector cells in vivo in a multidrug-resistant xenograft model by demonstrating that 4-HPR mediated an increase in target antigen GD2 and DRs expression (Fas and TRAIL-R2, (Fig. 3.8.1)) and enhanced ADCC and AICC (Fig. 3.8.2). Interestingly, we observed in vivo that the GD2specific, ch14.18-mediated ADCC in our setting is a major effector mechanism compared to the AICC response (Fig. 3.8.2), which is reversed to the data we obtained in vitro. This result is very promising since the AICC activity of NB patient NK cells is very donor-dependent based on donor KIR, HLA, and licensing patterns and varies greatly among patients. The fact that this is correlated with an increased NK cell infiltration (Fig. 3.8.3) into tumor tissue indicates that the effects of fenretinide are much more diverse than we thought and that more research is needed to characterize these effects in detail.

In summary, we have shown that direct combination of 4-HPR with ch14.18/CHO-based immunotherapy sensitizes NB cells for ch14.18-dependent NK cell and complement killing, two well-established effector mechanisms in anti-neuroblastoma immunotherapy with ch14.18. Additionally, 4-HPR increases NB cell sensitivity for AICC, which is in part mediated by a death receptor up regulation (TRAIL-R2), but also through an increased GrB and perforin production by the effector cells. Thus, our data suggest that a direct combination of ch14.18/CHO immunotherapy with 4-HPR could be beneficial for high-risk NB patients. 


\section{Summary}

\section{Summary.}

Neuroblastoma (NB) is an aggressive pediatric malignancy of the sympathetic nervous system responsible for $12 \%$ of cancer-associated mortality in children less than 15 years old. Recently, the addition of passive immunotherapy with the anti-GD2 antibody ch14.18 provided a clinical benefit with a $20 \%$ improvement in 2-year prevention of relapse for children with high-risk disease. However, still one third of the patients die from their disease emphasizing the need for improved therapy protocols. 4-HPR is a synthetic retinoid known to induce apoptosis in variety of cancer cells mainly via the accumulation of ceramides. 4-HPR is also known to induce the up regulation of death receptors resulting in an enhanced apoptosis via DR pathway.

In our work we tested the hypothesis whether treatment with 4-HPR will enhance antibodyindependent cellular cytotoxicity (AICC) and ch14.18-mediated anti-neuroblastoma effector functions (CDC, ADCC).

We demonstrate that pre-treatment of fenretinide-resistant NB cells with 4-HPR significantly enhanced ch14.18-mediated CDC and ADCC as well as AICC by both human NK cells and PBMCs. Interestingly, we also found an increase of the GD2 binding index and an increase of DRs in all cell lines tested. Our data suggest that the increased overall cytotoxicity towards 4-HPR treated NB cells is based on an up-regulation of GD2 and DRs. Further, we could show that blocking of ganglioside synthesis results in decrease of GD2 expression and nearly complete abrogation of the 4-HPR-mediated increase of ch14.18-dependent cytotoxicity of effector cells and complement, emphasizing a crucial role for GD2 expression as a mechanism for 4-HPRmediated sensitization of NB towards ch14.18-mediated immunotherapy. Interestingly, blocking of TRAIL-R2 resulted in a significant decrease of AICC, whereas blocking of Fas did not influence the increased AICC, however, the increased production of Granzyme B and perforin by effector cells upon co-culture with 4-HPR-treated NB cells strongly indicates the involvement of other supportive mechanisms, such as a change in expression levels of activating NK cells ligands on target cells.

Finally, we could show that tumor xenografts isolated from mice that were treated with 4HPR exhibit an increased GD2 binding index as well as DR expression compared to tumors isolated from vehicle treated animals. Importantly, this correlates well with a significantly higher ex vivo ADCC and AICC response of human NK cells towards 4-HPR treated tumors than to vehicle treated controls. Moreover, tumors from 4-HPR-treated mice showed a significantly higher percentage of tumor infiltrating NK cells compared to control tumors.

In summary, new therapy protocols are needed in order to optimize treatment of children with high-risk NB. We can show here for the first time that 4-HPR treatment sensitizes drugresistant human NB cells to ADCC and AICC by human NK cells and PBMCs, thereby providing 
Summary

an important baseline for the combination of 4-HPR and passive immunotherapy with ch14.18 in future clinical trials. 


\section{Literature}

\section{Literature.}

1. Wood L, Lowis S. An up-date on neuroblastoma. Pediatrics and child health 2008; $18: 3: 123-8$.

2. Schwab M ,Westermann F, Hero B, and Berthold F. Neuroblastoma: biology and molecular and chromosomal pathology. The Lancet Oncology 2003;4:472-80.

3. Pritchard J, Hickman JA. Why does stage 4s neuroblastoma regress spontaneously? Lancet 1994;344(8926):869-70.

4. Matthay KK, Reynolds CP, Seeger RC, Shimada H, Adkins ES, Haas-Kogan D, Gerbing RB, London WB, Villablanca JG. Long-term results for children with high-risk neuroblastoma treated on a randomized trial of myeloablative therapy followed by 13-cisretinoic acid: a children's oncology group study. J Clin Oncol 2009;27(7):1007-13.

5. Ehrlich, P. Collected studies on immunity. New York, NY: J. Wiley \& Sons; 1906.

6. Natsume A, Niwa R, Satoh M. Improving effector functions of antibodies for cancer treatment: Enhancing ADCC and CDC. Drug Des Devel Ther. 2009;3:7-16.

7. Vogel CL, Cobleigh MA, Tripathy D, et al. Efficacy and safety of trastuzumab as a single agent in first-line treatment of HER2-overexpressing metastatic breast cancer. J Clin Oncol 2002;20:719-726.

8. de Bono JS, Rowinsky EK. The ErbB receptor family: a therapeutic target for cancer. Trends Mol Med. 2002;8:S19-26.

9. Grillo-López AJ. Rituximab (Rituxan/MabThera): the first decade (1993-2003). Expert Rev Anticancer Ther. 2003;3:767-779.

10. Morgan A, Jones ND, Nesbitt AM, Chaplin L, Bodmer MW, Emtage JS. The N-terminal end of the $\mathrm{CH} 2$ domain of chimeric human IgG1 anti-HLA-DR is necessary for $\mathrm{C} 1 \mathrm{q}, \mathrm{Fc}$ gamma RI and Fc gamma RIII binding. Immunology 1995;86(2):319-24.

11. Janeway CA, Jr. et al. Immunology, $5^{\text {th }}$ edition.

12. Neumann J. Immunbiologie. Springer 2008. ISBN 978-3-540-72568-8.

13. Yang RK and Sondel PM. Anti-GD2 Strategy in the Treatment of Neuroblastoma. Drugs Future. 2010 ; 35(8): 665-.

14. Navid F, Armstrong M, Barfield RC. Immune therapies for neuroblastoma. Cancer Biol Ther. 2009;8(10):874-82.

15. Trapani JA. Granzymes: a family of lymphocyte granule serine proteases. Genome Biol 2001; 2(12):3014.1-3014.7.

16. Grossman WJ et al. Curr Opin Immunol.2003;15(6):731

17. Cullen SP, Brunet M, Martin SJ. Granzymes in cancer and immunity. Cell Death Differ 2010;17(4):616-23.

18. Weiner GJ. Rituximab: mechanism of action. Semin Hematol. 2010;47(2):115-23. 


\section{Literature}

19. Tegla CA, Cudrici C, Rus V, Ito T, Vlaicu S, Singh A, Rus H. Neuroprotective effects of the complement terminal pathway during demyelination: implications for oligodendrocyte survival. J Neuroimmunol. 2009;213(1-2):3-11.

20. Trinchieri,G., Biology of natural killer cells. Adv.Immunol 1989. 47: 187-376.

21. Robertson MJ, Ritz J. Biology and clinical relevance of human natural killer cells. Blood 1990;76(12):2421-38.

22. Cooper MA, Fehniger TA, Caligiuri MA. The biology of human natural killer-cell subsets. Trends Immunol 2001;22(11):633-40.

23. Moretta L, Bottino C, Pende D, Mingari MC, Biassoni R, Moretta A. Human natural killer cells: their origin, receptors and function. Eur J Immunol 2002;32:1205-1211.

24. Long EO. Regulation of immune response through inhibitory receptors. Annu Rev Immunol 1999;17:875-904.

25. Lanier LL. NK cell receptors. Annu Rev Immunol 1998;16:359-393.

26. Murphy C, Nikodem D, Howcroft K, Weissman JD, Singer DS. Active repression of major histocompatibility complex class I genes in a human neuroblastoma cell line. J Biol Chem 1996;271:30992-9.

27. Baker SJ, Reddy EP. Modulation of life and death by the TNF receptor superfamily. Oncogene 1998;17(25):3261-70.

28. Falschlehner C, Schaefer U, Walczak H. Following TRAIL's path in the immune system. Immunology. 2009;127(2):145-54.

29. Sayers TJ, Murphy WJ. Combining proteasome inhibition with TNF-related apoptosisinducing ligand (Apo2L/TRAIL) for cancer therapy. Cancer Immunol Immunother 2006;55: $76-84$.

30. LeBlanc HN and A Ashkenazi A. Apo2L/TRAIL and its death and decoy receptors. Cell Death and Differentiation 2003;10:66-75.

31. Huebener N, Fest S, Strandsby A, Michalsky E, Preissner R, Zeng Y, Gaedicke G, Lode HN. A rationally designed tyrosine hydroxylase DNA vaccine induces specific antineuroblastoma immunity. Mol Cancer Ther 2008;7:2241-2251.

32. Fest S, Huebener N, Weixler S, Bleeke M, Zeng Y, Strandsby A, Volkmer-Engert R, Landgraf C, Gaedicke G, Riemer AB, Michalsky E, Jaeger IS, Preissner R, Forster-Wald E, Jensen-Jarolim E, Lode HN. Characterization of GD2 peptide mimotope DNA vaccines effective against spontaneous neuroblastoma metastases. Cancer Res 2006;66:10567-10575.

33. Fest S, Huebener N, Bleeke M, Durmus T, Stermann A, Woehler A, Baykan B, Zenclussen AC, Michalsky E, Jaeger IS, Preissner R, Hohn O, Weixler S, Gaedicke G, Lode HN. 


\section{Literature}

Survivin minigene DNA vaccination is effective against neuroblastoma. Int $\mathbf{J}$ Cancer 2009;125(1):104-14.

34. Geiger JD, Hutchinson RJ, Hohenkirk LF, McKenna EA, Yanik GA, Levine JE, Chang AE, Braun TM, Mule JJ. Vaccination of pediatric solid tumor patients with tumor lysate-pulsed dendritic cells can expand specific $\mathrm{T}$ cells and mediate tumor regression. Cancer Res 2001;61:8513-8519.

35. Caruso DA, Orme LM, Amor GM, Neale AM, Radcliff FJ, Downie P, Tang ML, Ashley DM. Results of a Phase I study utilizing monocyte-derived dendritic cells pulsed with tumor RNA in children with Stage 4 neuroblastoma. Cancer 2005;103:1280-1291.

36. Siapati KE, Barker S, Kinnon C, Michalski A, Anderson R, Brickell P, Thrasher AJ, Hart SL. Improved antitumour immunity in murine neuroblastoma using a combination of IL-2 and IL-12. Br J Cancer 2003;88:1641-1648.

37. Salcedo R, Hixon JA, Stauffer JK, Jalah R, Brooks AD, Khan T, Dai RM, Scheetz L, Lincoln E, Back TC, Powell D, Hurwitz AA, Sayers TJ, Kastelein R, Pavlakis GN, Felber BK, Trinchieri G, Wigginton JM. Immunologic and therapeutic synergy of IL-27 and IL-2: enhancement of $\mathrm{T}$ cell sensitization, tumor-specific CTL reactivity and complete regression of disseminated neuroblastoma metastases in the liver and bone marrow. J Immunol 2009;182(7):4328-38.

38. Shiloni E, Eisenthal A, Sachs D, Rosenberg SA. Antibody-dependent cellular cytotoxicity mediated by murine lymphocytes activated in recombinant interleukin 2. J Immunol 1987;138:1992-1998.

39. Frost JD, Hank JA, Reaman GH, Frierdich S, Seeger RC, Gan J, Anderson PM, Ettinger LJ, Cairo MS, Blazar BR, Krailo MD, Matthay KK, Reisfeld RA, Sondel PM. A phase I/IB trial of murine monoclonal anti-GD2 antibody 14.G2a plus interleukin-2 in children with refractory neuroblastoma: a report of the Children's Cancer Group. Cancer 1997;80:317333.

40. Yu AL, Batova A, Alvarado C, Rao VJ, Castelberry RP. Usefulness of a chimeric anti-GD2 (ch14.18) and GM-CSF for refractory neuroblastoma: a POG phase II study. Proc. Am. Soc. Clin. Oncol 1997;16:1846.

41. Gilman AL, Ozkaynak MF, Matthay KK, Krailo M, Yu AL, Gan J, Sternberg A, Hank JA, Seeger R, Reaman GH, Sondel PM. Phase I study of ch14.18 with granulocyte-macrophage colonystimulating factor and interleukin-2 in children with neuroblastoma after autologous bone marrow transplantation or stem-cell rescue: a report from the Children's Oncology Group. J Clin Oncol 2009;27(1):85. 


\section{Literature}

42. Cheung NK, Saarinen UM, Neely JE, Landmeier B, Donovan D, Coccia PF. Monoclonal antibodies to a glycolipid antigen on human neuroblastoma cells. Cancer Res 1985;45(6):2642-2649.

43. Cheresh DA, Pierschbacher MD, Herzig MA, Mujoo K. Disialogangliosides GD2 and GD3 are involved in the attachment of human melanoma and neuroblastoma cells to extracellular matrix proteins. J Cell Biol 1986;102:688-696.

44. Svennerholm L, Bostrom K, Fredman P, Jungbjer B, Lekman A, Mansson JE, Rynmark BM. Gangliosides and allied glycosphingolipids in human peripheral nerve and spinal cord. Biochim Biophys Acta 1994;1214(2):115-23.

45. Cheung NK, Lazarus H, Miraldi FD, Abramowsky CR, Kallick S, Saarinen UM, Spitzer T, Strandjord SE, Coccia PF, Berger NA. Ganglioside GD2 specific monoclonal antibody 3F8: a phase I study in patients with neuroblastoma and malignant melanoma. J Clin Oncol 1987;5:1430-1440.

46. Cheung NK, Kushner BH, Yeh SD, Larson SM. 3F8 monoclonal antibody treatment of patients with stage 4 neuroblastoma: a phase II study. Int J Oncol 1998;12:1299-1306.

47. Kushner BH, Kramer K, Cheung NK. Phase II trial of the anti-G(D2) monoclonal antibody 3F8 and granulocyte-macrophage colony-stimulating factor for neuroblastoma. J Clin Oncol 2001;19(22):4189-4194.

48. Murray JL, Cunningham JE, Brewer H, Mujoo K, Zukiwski AA, Podoloff DA, Kasi LP, Bhadkamkar V, Fritsche HA, Benjamin RS, et al. Phase I trial of murine monoclonal antibody $14 \mathrm{G} 2 \mathrm{a}$ administered by prolonged intravenous infusion in patients with neuroectodermal tumors. J Clin Oncol 1994;12:184-193.

49. Frost JD, Hank JA, Reaman GH, Frierdich S, Seeger RC, Gan J, Anderson PM, Ettinger LJ, Cairo MS, Blazar BR, Krailo MD, Matthay KK, Reisfeld RA, Sondel PM. A phase I/IB trial of murine monoclonal anti-GD2 antibody 14.G2a plus interleukin-2 in children with refractory neuroblastoma: a report of the Children's Cancer Group. Cancer 1997;80:317333.

50. Gillies SD, Lo KM, and Wesolowski J. High-level expression of chimeric antibodies using adapted cDNA variable region cassettes. J. Immunol Methods 1989;125:191-202.

51. Barker E, Mueller BM, Handgretinger R, Herter M, Yu AL, Reisfeld RA. Effect of a chimeric antiganglioside GD2 antibody on cell-mediated lysis of human neuroblastoma cells. Cancer Res 1991 Jan 1;51(1):144-149.

52. Yu AL, Gilman AL, Ozkaynak MF, London WB, Kreissman S, Chen H, Smith M, Anderson B, Villablanca J, Matthay KK, Shimada H, Grupp SA, et al. Chimeric Anti-GD2 Antibody with GM-CSF, IL2 and 13-cis Retinoic Acid for High-risk Neuroblastoma: A Children's Oncology Group (COG) Phase 3 Study. N Engl J Med 2010; 363: 1324-1334. 


\section{Literature}

53. Reisfeld RA, Gillies SD. Antibody-interleukin-2 fusion proteins: a new approach to cancer therapy. J Clin Lab Anal 1996; 10: 160-6.

54. King DM, Albertini MR, Schalch H, et al. A phase i clinical trial of the immunocytokine EMD 273063 (hu14.18-IL2) in patients with melanoma. J Clin Oncol 2004; 22: 4463-73.

55. Lode HN, Xiang R, Dreier $\mathrm{T}$, et al: Natural killer cell-mediated eradication of neuroblastoma metastases to bone marrow by targeted interleukin-2 therapy. Blood 1998; 91: 1706-1715.

56. Matthay KK, Reynolds CP, Seeger RC, Shimada H, Adkins ES, Haas-Kogan D, Gerbing $\mathrm{RB}$, London WB, and Villablanca JG: Long-term results for children with high-risk neuroblastoma treated on a randomized trial of myeloablative therapy followed by 13-cisretinoic acid: a Children's Oncology Group study. J Clin Oncol 2007; 25: 1054-1060.

57. Inoue M, Nakano T, Yoneda A, Nishikawa M, Nakayama M, Yumura-Yagi K, Sakata N, Yasui M, Okamura T, Kawa K. Graft-versus-tumor effect in a patient with advanced neuroblastoma who received HLA haplo-identical bone marrow transplantation. Bone Marrow Transplant 2003; 32: 103-106.

58. Yoshida H, Kusuki S, Hashii Y, Ohta H, Morio T, Ozono K. Ex vivo-expanded donor CD4(+) lymphocyte infusion against relapsing neuroblastoma: A transient graft-versustumor effect. Pediatr Blood Cancer. 2009; 52: 7: 895-7.

59. Park JR, DiGiusto DL, Slovak M, Wright C, Naranjo A, Wagner J, Meechoovet HB, Bautista C, Chang WC, Ostberg JR and Jensen MC. Adoptive transfer of chimeric antigen receptor re-directed cytolytic $\mathrm{T}$ lymphocyte clones in patients with neuroblastoma. Molecular Therapy 2007; 15: 4: 825-833.

60. Seidel D, Shibina A, Esser R, Koehl U, Wels W, Huebener N, Lode HN. The chimeric antigen receptor $\mathrm{scFv}(\mathrm{ch} 14.18)$ mediates effective NK cell killing of GD2-expressing, drugresistant neuroblastoma. (submission).

61. Handgretinger R, Bruchelt G, Kimmig A, Dopfer R, Niethammer D, Treuner J. In-vitro induction of lymphokine-activated killer (LAK) activity in patients with neuroblastoma. Pediatr Hematol Oncol 1989; 6: 4: 307-17.

62. Veronesi U, Mariani L, Decensi A, Formelli F, Camerini T, Miceli R, Di Mauro MG, Costa A, Marubini E, Sporn MB, De PG. Fifteen-year results of a randomized phase III trial of fenretinide to prevent second breast cancer. Ann Oncol 2006;17:7:1065-71.

63. Villablanca JG, Krailo MD, Ames MM, Reid JM, Reaman GH, Reynolds CP. Phase I trial of oral fenretinide in children with high-risk solid tumors: a report from the Children's Oncology Group (CCG 09709). J Clin Oncol 2006;24: 21:3423-30. 


\section{Literature}

64. Oridate N, Suzuki S, Higuchi M, Mitchell MF, Hong WK, Lotan R. Involvement of reactive oxygen species in $\mathrm{N}$-(4-hydroxyphenyl)retinamide-induced apoptosis in cervical carcinoma cells. J Natl Cancer Inst 1997; 89: 1191-8.

65. Delia D, Aiello A, Meroni L, Nicolini M, Reed JC, Pierotti MA. Role of antioxidants and intracellular free radicals in retinamide-induced cell death. Carcinogenesis 1997; 18: 943-8.

66. Maurer BJ, Metelitsa LS, Seeger RC, Cabot MC, Reynolds CP. Increase of ceramide and induction of mixed apoptosis/necrosis by $\mathrm{N}$-(4-hydroxyphenyl)-retinamide in neuroblastoma cell lines. J Natl Cancer Inst 1999; 91:1 138-46.

67. Hannun YA. Functions of ceramide in coordinating cellular responses to stress. Science 1996; 274: 1855-9.

68. Ogretmen B, Hannun YA. Updates on functions of ceramide in chemotherapy-induced cell death and in multidrug resistance. Drug Resist Updat 2001; 4: 6: 368-77.

69. Lovat PE, Di SF, Corazzari M, Fazi B, Donnorso RP, Pearson AD, Hall AG, Redfern CP, Piacentini M. Gangliosides link the acidic sphingomyelinase-mediated induction of ceramide to 12-lipoxygenase-dependent apoptosis of neuroblastoma in response to fenretinide. J Natl Cancer Inst 2004;96(17):1288-99.

70. Illuzzi G, Bernacchioni C, Aureli M, Prioni S, Frera G, Donati C, Valsecchi M, Chigorno V, Bruni P, Sonnino S, Prinetti A. Sphingosine kinase mediates resistance to the synthetic retinoid $\mathrm{N}$-(4-hydroxyphenyl)retinamide in human ovarian cancer cells. J Biol Chem 2010;285(24):18594-602.

71. Pchejetski D, Golzio M, Bonhoure E, Calvet C, Doumerc N, Garcia V, Mazerolles C, Rischmann P, Teissie J, Malavaud B, Cuvillier O. Sphingosine kinase-1 as a chemotherapy sensor in prostate adenocarcinoma cell and mouse models. Cancer Res 2005;65(24):1166775.

72. Itoh M, Kitano T, Watanabe M, Kondo T, Yabu T, Taguchi Y, Iwai K, Tashima M, Uchiyama T, Okazaki T. Possible role of ceramide as an indicator of chemoresistance: decrease of the ceramide content via activation of glucosylceramide synthase and sphingomyelin synthase in chemoresistant leukemia. Clin Cancer Res 2003;9(1):415-23.

73. Prinetti A, Basso L, Appierto V, Villani MG, Valsecchi M, Loberto N, Prioni S, Chigorno V, Cavadini E, Formelli F, Sonnino S. Altered sphingolipid metabolism in N-(4hydroxyphenyl)-retinamide-resistant A2780 human ovarian carcinoma cells. J Biol Chem 2003;278(8):5574-83. 


\section{Literature}

74. White DE, Burchill SA. Fenretinide-dependent upregulation of death receptors through ASK1 and p38alpha enhances death receptor ligand-induced cell death in Ewing's sarcoma family of tumours. Br J Cancer 2010.

75. Seeger RC, Reynolds CP. Treatment of high-risk solid tumors of childhood with intensive therapy and autologous bone marrow transplantation. Pediatr Clin North Am. 1991;38(2):393-424.

76. Keshelava N, Seeger RC, Groshen S, Reynolds CP. Drug resistance patterns of human neuroblastoma cell lines derived from patients at different phases of therapy. Cancer Res 1998;58(23):5396-405.

77. Senchenkov A, Litvak DA, Cabot MC. Targeting ceramide metabolism-a strategy for overcoming drug resistance. J Natl Cancer Inst. 2001;93(5):347-57.

78. Cai Z, Bettaieb A, Mahdani NE, Legrès LG, Stancou R, Masliah J, Chouaib S. Alteration of the sphingomyelin/ceramide pathway is associated with resistance of human breast carcinoma MCF7 cells to tumor necrosis factor-alpha-mediated cytotoxicity. J Biol Chem 1997;272:6918-26.

79. Liu YY, Han TY, Yu JY, Bitterman A, Le A, Giuliano AE, Cabot MC. Oligonucleotides blocking glucosylceramide synthase expression selectively reverse drug resistance in cancer cells. J Lipid Res 2004;45(5):933-40

80. Maurer BJ, MeltonL, Billups C, Cabot MC and Reynolds CP. Synergistic cytotoxicity in solid tumor cell lines between N-(4-hydroxyphenyl)retinamide and modulators of ceramide metabolism. J Natl Cancer Inst 2000;92:1897-1909.

81. Garaventa A, Luksch R, Lo Piccolo MS, Cavadini E, Montaldo PG, Pizzitola MR, Boni L, Ponzoni M, Decensi A, De BB, Bellani FF, Formelli F. Phase I trial and pharmacokinetics of fenretinide in children with neuroblastoma. Clin Cancer Res 2003;9(6):2032-9.

82. Kouhara J, Yoshida T, Nakata S, Horinaka M, Wakada M, Ueda Y, Yamagishi H, Sakai T. Fenretinide up-regulates DR5/TRAIL-R2 expression via the induction of the transcription factor CHOP and combined treatment with fenretinide and TRAIL induces synergistic apoptosis in colon cancer cell lines. Int J Oncol 2007;30(3):679-87.

83. Jinushi M, Takehara T, Tatsumi T, Kanto T, Groh V, Spies T, Kimura R, Miyagi T, Mochizuki K, Sasaki Y, Hayashi N. Expression and role of MICA and MICB in human hepatocellular carcinomas and their regulation by retinoic acid. Int $\mathbf{J}$ Cancer 2003;104(3):354-61.

84. Carlson LM, Påhlman S, De Geer A, Kogner P, Levitskaya J. Differentiation induced by physiological and pharmacological stimuli leads to increased antigenicity of human neuroblastoma cells. Cell Res. 2008;18(3):398-411. 


\section{Literature}

85. Murphy C, Nikodem D, Howcroft K, Weissman JD, Singer DS. Active repression of major histocompatibility complex class I genes in a human neuroblastoma cell line. J Biol Chem 1996;271:30992-9.

86. Deng W, Li R, Ladisch S. Influence of cellular ganglioside depletion on tumor formation. J Nat Cancer Inst 2000,92(11):912-17.

87. Hoon DS, Kuo CT, Wen S, Wang H, Metelitsa L, Reynolds CP, Seeger RC. Ganglioside GM2/GD2 synthetase mRNA is a marker for detection of infrequent neuroblastoma cells in bone marrow. Am J Pathol 2001;159(2):493-500.

88. Masters JR, Thomson JA, Daly-Burns B, Reid YA, Dirks WG, Packer P, Toji LH, Ohno T, Tanabe H, Arlett CF, Kelland LR, Harrison M, et al. Short tandem repeat profiling provides an international reference standard for human cell lines. Proc Natl Acad Sci U S A 2001;98(14):8012-7.

89. Reynolds CP, Biedler JL, Spengler BA, Reynolds DA, Ross RA, Frenkel EP, et al. Characterization of human neuroblastoma cell lines established before and after therapy. $\mathbf{J}$ Natl Cancer Inst 1986;76:375-87

90. Somanchi SS, Senyukov VV, Denman CJ, Lee DA. Expansion, purification, and functional assessment of human peripheral blood NK cells. J Vis Exp 2011;(48).

91. Dallegri F, Ballestrero A, Ottonello L, Patrone F. Defective antibody-dependent tumour cell lysis by neutrophils from cancer patients. Clin Exp Immunol.1989;77(1):58-61.

92. Cheung NK, Modak S. Oral (1-->3),(1-->4)-beta-D-glucan synergizes with antiganglioside GD2 monoclonal antibody 3F8 in the therapy of neuroblastoma. Clin Cancer Res 2002;8(5):1217-23.

93. Cuello M, Coats AO, Darko I, Ettenberg SA, Gardner GJ, Nau MM, Liu JR, Birrer MJ, Lipkowitz S. N-(4-hydroxyphenyl) retinamide (4HPR) enhances TRAIL-mediated apoptosis through enhancement of a mitochondrial-dependent amplification loop in ovarian cancer cell lines. Cell Death Differ. 2004;11(5):527-41. 
Appendix

\section{Curriculum Vitae.}

Mein Lebenslauf wird aus datenschutzrechtlichen Gründen in der elektronischen Version meiner Arbeit nicht veröffentlicht. 
Appendix

\section{Publications:}

1. Shibina A, Seidel D, Somanchi S, Lee DA, Reynolds CP, Huebener N. Fenretinide sensitizes multi-drug resistant neuroblastoma for ch14.18-mediated NK cell lysis. (J Mol med, in print).

2. Seidel D, Shibina A, Esser R, Koehl U, Wels W, Huebener N, Lode HN. The chimeric antigen receptor $s c F v(c h 14.18)$ mediates effective NK cell killing of GD2-expressing, drugresistant neuroblastoma. (close to submission). 


\section{Acknowledgment.}

Completing a dissertation is truly a marathon event, and I would not have been able to complete this run without the aid and support of countless people over the past four years.

I would like to thank Prof. Dr. Holger N. Lode for giving me the opportunity to work in his lab and for being a great chef.

I would like to thank my supervisor, Dr. Nicole Hübener, for her encouragement, understanding, supervision and kindness. I appreciate her support over the four years, her assistance in writing letters and reports and her patience in reading and correcting the whole manuscript thoroughly. During my first year in Berlin she not only introduced me to the lab work, but gave me important advice "How to survive in Germany" (alles aufheben). We spend a lot of time discussing not only the project, but relationship, music and books and became friends. We went 1000 miles to see the Atlantic Ocean and have a rest for 1 day from the hard lab work. Thank you, Nicole, for being good teacher and good friend.

Very special thanks goes for my friend and lab mate Diana Seidel for her help at all levels of the research project, our philosophical debates, exchanges of knowledge, skills and for being a great neighbor in Lubbock, Texas. Thank you for reading this work and providing me with valuable comments. Over this time we shared not only the rooms during the congress (especially designer room in München) but also excitement and frustrations, which belong to a researcher's existence. I learned a lot from you. And, honestly, I was trying to do my best, even when I mixed all your cell lines or spitted them too much.

My thanks to my colleagues from AG Lode for the great time I had in our group. I enjoyed the atmosphere, their friendship, and their support. My thanks to Alexander Stermann, Matthias Bleeke, Bianca Baykan, Silke Weixler, Catharina Delebinski, Kristin Kemnitz-Hassanin for the great collaboration. Especially, I would like to thank the Berliner Lab for providing us with German food in Texas.

I would like to thank Prof. Dr. Gerhard Gaedicke for his encouragement and kindness over the years.

I am very thankful to Prof Dr Tatjana Nastausheva from my Alma Mater for her endless support during my study and over last the four years.

I also would like to thank the International Institute of Medical Education and Cooperation in Voronezh, especially Ljudmila Zhutschenko, for their help, practical and intellectual advice and patience.

I thank my parents and my family, whose love and support were always there when I needed it, even from thousands of miles away. A special thanks goes out for my husband Mario for his constant presence, care, patience and for supporting my crazy ideas such as move to Texas or a car 
Appendix

trip to New York. I also would like to thank my best friends (M and $\mathrm{J} \odot)$ ) for their friendship, instant moral support and visiting me over the world. 
Appendix

\section{Versicherung an Eides Statt.}

Hiermit erkläre ich, dass ich die vorgelegte Dissertation selbst verfasst und keine anderen als die angegebenen Quellen und Hilfsmittel benutzt, ohne die (unzulässige) Hilfe Dritter verfasst und auch in Teilen keine Kopien anderer Arbeiten dargestellt habe.

Berlin in April 2012

Anastasia Shibina 